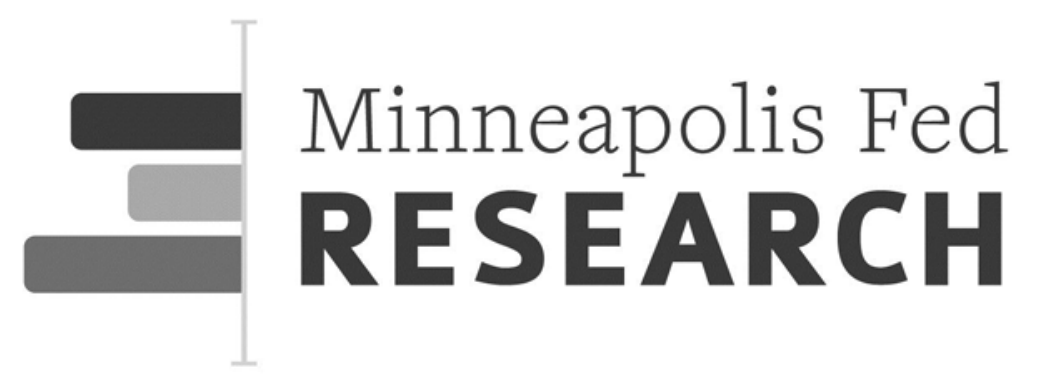

\title{
Liquidity Traps and Monetary Policy: Managing a Credit Crunch
}

\author{
Francisco Buera \\ Federal Reserve Bank of Chicago and NBER \\ Juan Pablo Nicolini \\ Federal Reserve Bank of Minneapolis and Universidad Di Tella
}

Staff Report 540

February 2017

Keywords: Liquidity trap; Credit crunch; Collateral constraints; Monetary policy, Ricardian equivalence JEL classification: E44, E52, E58, E63

The views expressed herein are those of the authors and not necessarily those of the Federal Reserve Bank of Chicago, the Federal Reserve Bank of Minneapolis, or the Federal Reserve System.

Federal Reserve Bank of Minneapolis • 90 Hennepin Avenue • Minneapolis, MN 55480-0291

https://www.minneapolisfed.org/research/ 


\title{
Liquidity Traps and Monetary Policy: Managing a Credit Crunch
}

\author{
Francisco Buera * Juan Pablo Nicolini ${ }^{\ddagger}$
}

February, 2017

\begin{abstract}
We study a model with heterogeneous producers that face collateral and cash-in-advance constraints. A tightening of the collateral constraint results in a credit-crunch-generated recession that reproduces several features of the financial crisis that unraveled in 2007 in the United States. The model can be used to study the effects of the credit-crunch on the main macroeconomic variables and the impact of alternative policies. The policy implications regarding forward guidance are in contrast with the prevalent view in most central banks, based on the New Keynesian explanation of the liquidity trap.
\end{abstract}

*Federal Reserve Bank of Chicago; francisco.buera@chi.frb.org.

${ }^{\dagger}$ Federal Reserve Bank of Minneapolis and Universidad Di Tella; juanpa@minneapolisfed.org.

${ }_{\ddagger}^{\ddagger}$ We want to thank Marco Basetto, Jeff Campbell, Gauti Eggertsson, Jordi Gali, Simon Gilchrist, Hugo Hopenhayn, Oleg Itskhoki, Keichiro Kobayashi and Pedro Teles. The views expressed herein are those of the authors and not necessarily those of the Federal Reserve Bank of Chicago, Federal Reserve Bank of Minneapolis, or the Federal Reserve System. 


\section{Introduction}

In this paper, we study the effect of monetary and debt policy following a negative shock to the efficiency of the financial sector. We build a model that combines the financial frictions literature, such as Kiyotaki (1998), Moll (2014), and Buera and Moll (2015), with the monetary literature, such as Lucas (1982) and Svensson (1985). The first branch of the literature gives rise to a non trivial financial market by imposing collateral constraints on debt contracts. The second gives rise to a money market by imposing cash-in-advance constraints on purchases. We show that a calibrated version of the model can quantitatively match several salient features of the US experience since 2007. We use the model to evaluate alternative policies.

The year 2008 will long be remembered in the macroeconomics literature. This is so not only because of the massive shock that hit global financial markets but also because of the unusual and extraordinary policy response that followed. The Federal Reserve doubled its balance sheet in just three months - from $\$ 900$ billion on September 1 to $\$ 2.1$ trillion by December 1 , and it reached around $\$ 3$ trillion by the end of 2012 . At the same time, large fiscal deficits implied an increase in the supply of government bonds, net of the holdings by the Fed, of roughly $30 \%$ of total output in just a few years, a change never seen during peace-time in the United States. Similar measures were taken in other developed economies.

The most prominent models used for policy evaluation at the time of the crisis ignored the financial sector on the one hand and the role of changes in outside liquidity on the other. ${ }^{1}$ There were good historical reasons for both: big financial shocks have seemed to belong exclusively to emerging economies since the turbulent 1930s. In addition, monetary economics developed during the last two decades around the central bank rhetoric of exclusively emphasizing the short-term nominal interest rate, whereas measures of liquidity or money were completely ignored as a stance of monetary policy. But 2008 seriously challenged both generally accepted views. Consequently, we need general equilibrium models that can be used for policy evaluation during times of financial distress. The purpose of this paper is to provide one such model and to analyze the macroeconomic effects of alternative policies.

An essential role of financial markets is to reallocate capital from wealthy indi-

\footnotetext{
${ }^{1}$ These models have been further adapted to try to address these issues (see Christiano et al. (2011) or Werning (2011)). As we will discuss, our model captures different effects, and the policy implications differ substantially.
} 
viduals with no profitable investment projects to individuals with profitable projects and no wealth. The efficiency of these markets determines the equilibrium allocation of physical capital across projects and therefore equilibrium intermediation and total output. The financial frictions literature, from which we build, studies models of intermediation with these properties, the key friction being an exogenous collateral constraint on investors. ${ }^{2}$ The equilibrium allocation critically depends on the nature of the collateral constraints: the tighter the constraints, the less efficient the allocation of capital and the lower are total factor productivity and output, so a tightening of the collateral constraint creates disintermediation and a recession. We interpret this reduction in the ability of financial markets to properly allocate capital across projects as the negative shock that hit the US economy at the end of $2007 .^{3}$

We modify this basic model by imposing a cash-in-advance constraint on households that gives rise to a demand for money balances. This allows us to study the effect of changes in the outside supply of liquid assets. The zero lower bound on the interest rate emerges as an equilibrium condition to avoid arbitrage opportunities. If inflation is low enough, once a credit crunch unravels that is severe enough to bring the real interest rate to negative values - as we saw in the United States after 2007 - the zero bound on nominal interest rates may bind. We show that in this case, if the government does not change the outside supply of liquid assets (which at the zero bound is the sum of money and government bonds), a deflation follows. The reason is that the credit crunch causes the return on privately issued assets to go down to the point (assuming a binding zero bound) where outside assets would be strictly preferred by savers. This excess demand for outside liquid assets implies a deflation, unless the nominal supply is increased.

In the benchmark case of flexible prices and indexed private debt contracts, this deflation is innocuous, having negligible real effects. However, if private debt contracts are promises to return dollars instead of goods, a debt deflation problem that accentuates the recession arises, resembling the problem pointed out by Fisher (1933) in reference to the Great Depression. We also consider frictions in the setting of wages, as the New Keynesian literature emphasized. When both mechanisms are present, the recession can be dramatically magnified.

\footnotetext{
${ }^{2}$ We closely follow the work of Buera and Moll (2015), who apply the model originally developed by Moll (2014) to study business cycles, to analyze the role of credit markets in economic development. See Kiyotaki (1998) for an earlier version of a related framework.

${ }^{3}$ As we explain in detail in Section 4.1, the behavior of the real interest rate, the variable we use to identify the shock, dates the beginning of the recession in the third quarter of 2007.
} 
A solution to the deflation problem is an increase in outside liquidity (money and government bonds), well beyond what is required for transactional purposes. As it turns out, however, this increase in liquidity has additional real effects because Ricardian equivalence does not hold in this model: the collateral constraints imply that active entrepreneurs who are credit constrained face a real interest rate that is different from (higher than) the equilibrium real interest rate. We show that the increase in liquidity prevents the real interest rate from falling too much. We also show that this ameliorates the drop in productivity. But it also crowds out private investment, making the recovery from the recession much slower.

As we show in a simplified version of the model that can be solved analytically, if the shock to the collateral constraint that causes the recession is sufficiently large, the equilibrium real interest rate becomes negative and persistent as long as the shock is persistent. At the same time, investment goes down. We find these properties of the model particularly attractive because a very special feature of recent years is a substantial and persistent gap between real output and its trend, together with a substantial and persistent negative real interest rate and low investment rates.

The reason for the drop in real interest rates is that savings must be reallocated to lower productivity entrepreneurs, but they will only be willing to do so if the real interest rate is lower. To put it differently, the "demand" for loans falls, which in turn pushes down the real interest rate. Several other properties of the recession generated by a tightening of the collateral constraint in the model are in line with the events that have unfolded since 2008, such as the persistent negative real interest rate, the sustained periods with an effective zero bound on nominal interest rates, and the substantial drops in investment, total factor productivity, and output, all of which driven by a single shock. In addition, the model implies the need for a very large increase in liquidity while the zero bound binds to stabilized prices, two features present in the crisis.

The model has very few parameters. A quantitative version of the model, calibrated to match the evolution of the real interest rate, performs reasonably well for most variables that have not been targeted. The one exception is labor input, which dropped substantially in the United States after 2007, explains around half of the drop in output, and is constant in the model. We find this reasonable quantitative performance reassuring in using the model to perform policy analysis.

The paper proceeds as follows. In Section 2, we present the model and characterize 
the individual problems. In Section 3, we define an equilibrium and characterize its properties for a particular case that, by shutting down the endogenous evolution of the wealth distribution, can be solved analytically. In Section 4 we calibrate the full model and show how it behaves relative to the data once we take into account the injection of outside liquidity observed since 2008. We also perform several policy counterfactuals to study the policies undertaken in the United States starting in 2008. First, we solve for the equilibrium assuming there is no injection of liquidity on impact and that there is no further increase in the stock of government bonds (outside assets). As explained above, the model implies an initial deflation, followed by an inflation rate that is higher than the one in steady state. The calibrated model implies that the recession can be very large in this case if debt is nominal or there are sticky wages (or both). We then study active inflation-targeting policies for low values of the inflation target. In these cases, the deflation with its associated real effects can be avoided by a sufficiently large increase in the supply of government liabilities. This exercise is reminiscent of the discussion in Friedman and Schwartz (1963), who argued that the Fed should have substantially increased its balance sheet in order to avoid the deflation during the Great Depression. ${ }^{4}$ Does the different monetary policy recently adopted account for the Great Contraction being much less severe than the Great Depression? Our model suggests this may well be the case. ${ }^{5}$

In studying inflation-targeting policies, we show that the number of periods that the economy will be at the zero bound and the amount of liquidity that must be injected depend on the target for the rate of inflation. The evolution of output critically depends on the increase in liquidity. The target for inflation and the zero bound constraint on nominal rates imply a floor on how low the real interest rate can be. But for this to be an equilibrium, private savings must end up somewhere else: this is the role of the increase in government liabilities. As mentioned above, in this heterogeneous credit-constrained agents model, outside liquidity affects equilibrium interest rates even if taxes are lump sum. As a consequence, the issuance of government liabilities (money or bonds, which are perfect substitutes at the zero bound) crowds out

\footnotetext{
${ }^{4}$ In 2002, Bernanke, then a Federal Reserve Board governor, said in a speech in a conference celebrating Friedman's 90th birthday, "I would like to say to Milton and Anna: Regarding the Great Depression. You're right, we did it. We're very sorry. But thanks to you, we won't do it again" (speech published in Milton Friedman and Anna Jacobson Schwartz, The Great Contraction, 19291933) (Princeton, NJ: Princeton University Press, 2008), 227.

${ }^{5}$ Claiming that he "prevented an economic catastrophe," Time magazine named then-Chairman Bernanke Person of the Year on December 2009.
} 
private investment and slows down capital accumulation. But increases in liquidity have an additional effect. In the model, a credit crunch generates a recession because total factor productivity (TFP) falls. The reason, as we mentioned above, is that capital needs to be reallocated from high productivity entrepreneurs for which the collateral constraint binds to low productivity entrepreneurs for which the collateral constraint does not bind. An increase in liquidity prevents the real interest rate from falling too much and ameliorates the drop in productivity.

The model therefore challenges the interpretation of the events following 2009 provided by a branch of the literature that, using New Keynesian models, places a strong emphasis on the interaction between the zero bound constraint on nominal interest rates and price rigidities. ${ }^{6}$ This is also the dominant view of monetary policy at major central banks, including the Fed. According to this view, a shock-often associated with a shock to the efficiency of intermediation ${ }^{7}$ - drove the natural real interest rate into negative territory. The optimal monetary policy in those models is to set the nominal interest rate equal to the natural real interest rate. However, because of the zero bound, that is not possible. But it is optimal to keep the nominal interest rate at the zero bound, as the Fed has been doing for over seven years now. Furthermore, these models imply that it is unambiguously optimal to maintain the nominal interest rate at zero even after the negative shock reverts. This policy implication, called "forward guidance," has dominated the policy decisions in the United States since 2008 and remains the conceptual framework that justifies the "exit strategy."

On the contrary, the model we study stresses a different and novel trade-off between ameliorating the initial recession and delaying the recovery. When the central bank chooses a lower inflation target, it must inject more liquidity. As a result, the liquidity trap lasts longer and the real interest rate is constrained to be higher, ameliorating the drop in productivity. The counterpart of the milder drop in TFP is a drop in investment due to the crowding out, leading to a substantial and persistent decline in the stock of capital and a slower recovery.

Which is the optimal policy? In this heterogeneous agents model, answering that question requires taking a stand on Pareto weights. We do not pursue this line, but in the Online Appendix, we compute the distribution of welfare changes across all agents. A final section concludes.

\footnotetext{
${ }^{6}$ See Eggertsson and Woodford (2003), Christiano et al. (2011), Correia et al. (2013), and Werning (2011).

${ }^{7}$ See, for example, Curdia and Eggertsson (2009).
} 
Related Literature We consider a monetary version of the model in Buera and Moll (2015) and Moll (2014);Kiyotaki (1998) is an earlier example that focuses on a twopoint distribution of shocks to entrepreneurial productivity. This framework is related to a long tradition that studies the role of firms' balance sheets in business cycles and during financial crises, including Bernanke and Gertler (1989), Kiyotaki and Moore (1997), Bernanke et al. (1999), Cooley et al. (2004), Jermann and Quadrini (2012). ${ }^{8}$

Kiyotaki and Moore (2012) study a monetary economy in which entrepreneurs face stochastic investment opportunities and frictions to issue and resell equity on real assets. They also consider the aggregate effects of a shock to the ability to resell equity. In their environment, money is valuable provided that frictions to issue and resell equity are tight enough. They use their model to study the effect of open market operations that consist of the exchange of money for equity. Brunnermeier and Sannikov (2013) also study a monetary economy with financial frictions, emphasizing the endogenous determination of aggregate risk and the role of macro prudential policy. As in our model, a negative aggregate financial shock results in a deflation, although both of these papers consider environments in which, for the relevant cases, the zero lower bound on the nominal interest rate is binding in every period.

Guerrieri and Lorenzoni (2011) consider a model in which workers face idiosyncratic labor shocks where a credit crunch leads to an increase in the demand of bonds and therefore results in negative real rates. Although our model also generates a large drop in the real interest rate, the forces underlying this result are different. In our framework, the drop in the real interest rate is the consequence of a collapse in the ability of productive entrepreneurs to supply bonds (i.e., to borrow from the unproductive entrepreneurs and workers), as opposed to an increase in the demand for bonds by these agents. In our model, a credit crunch has an opposite, negative effect on investment.

\section{The Model}

In this section, we describe the model, which closely follows the framework in Moll (2014), modified by imposing a cash-in-advance constraint on the consumer's decision problem and by assuming permanent productivity types. The analysis will be restricted to a perfect foresight economy in which, starting at the steady state, all agents learn

\footnotetext{
${ }^{8}$ See Buera and Moll (2015) for a detailed discussion of the connection between the real version of our framework and related approaches in the literature.
} 
at time zero that, starting next period, the collateral constraint will be tightened for several periods.

\section{$2.1 \quad$ Households}

All agents have identical preferences, given by

$$
\sum_{t=0}^{\infty} \beta^{t}\left[\nu \log c_{1 t}^{j}+(1-\nu) \log c_{2 t}^{j}\right]
$$

where $c_{1 t}^{j}$ and $c_{2 t}^{j}$ are consumption of the cash good and of the credit good, for agent $j$ at time $t$, and $\beta<1$. Each agent also faces a cash-in-advance constraint,

$$
c_{1 t}^{j} \leq \frac{m_{t}^{j}}{p_{t}}
$$

where $m_{t}^{j}$ is the beginning of period money holdings and $p_{t}$ is the money price of consumption at time $t$.

The economy is inhabited by two classes of agents, a mass $L$ of workers and a mass 1 of entrepreneurs, which we now describe.

Entrepreneurs Entrepreneurs are heterogeneous with respect to their productivity (which is exogenous) and their wealth (which is endogenous). We assume that the productivity of each entrepreneur, $z \in Z \subset \mathbb{R}^{+}$, is constant through her lifetime. We let $\Psi(z)$ be the measure of entrepreneurs of type $z$. Every period, each entrepreneur must choose whether to be active in the following period (to operate a firm as a manager) or to be passive and offer her wealth in the credit market. Thus, each entrepreneur has four state variables: her financial wealth (capital plus bonds), money holdings, the occupational choice (active or passive) made last period, and productivity. She must decide the labor demand if active, how much to consume of each good, and whether to be active in the following period, and, if so, how much capital to invest in her own firm. An entrepreneur's investment is constrained by her financial wealth at the end of period $a$ and the amount of bonds she can sell $-b, k \leq-b+a$, where we assume that the amount of bonds that can be sold is limited by a simple collateral constraint of the form $-b^{j} \leq \theta k^{j}$, for some exogenously given $\theta \in[0,1){ }^{9}$

\footnotetext{
${ }^{9}$ If $\theta=1$, then all capital can be pledged and individual wealth plays no role. This is equivalent to imposing no collateral constraints so the model becomes a standard representative agent Solow model
} 
Type- $z$ entrepreneurs use capital and labor to produce output according to

$$
y=(z k)^{\alpha} l^{1-\alpha} .
$$

This constant returns technology implies that the net-of-labor-cost revenues of entrepreneurs are a linear function of capital stock, $\varrho z k$, where $\varrho=\alpha((1-\alpha) / w)^{(1-\alpha) / \alpha}$ is the return to the effective units of capital $z k$ and $w$ denotes the real wage. In contrast with span-of-control models, these entrepreneurs face constant marginal product of capital. Thus, as we show below, their optimal decisions exhibit a corner solution: either they are inactive or they borrow all the way up to their collateral constraint. ${ }^{10}$

The end-of-period investment and leverage choice of entrepreneurs with ability $z$ and wealth $a$ solves the following linear problem:

$$
\begin{aligned}
\max _{k, d} & \varrho z k+(1-\delta) k+(1+r) b \\
& k \leq a-b, \\
& -b \leq \theta k,
\end{aligned}
$$

where $r$ is the real interest rate. Because the problem is linear, the optimal capital and leverage choices are given by the following policy rules, with a simple threshold property,

$$
k(z, a)=\left\{\begin{array}{ll}
a /(1-\theta), & z \geq \hat{z} \\
0, & z<\hat{z}
\end{array}, \quad b(z, a)= \begin{cases}-(1 /(1-\theta)-1) a, & z \geq \hat{z} \\
a, & z<\hat{z},\end{cases}\right.
$$

where $\hat{z}$ solves $\varrho \hat{z}=r+\delta$. Given entrepreneurs' optimal investment and leverage decisions, they face a linear return to their non monetary wealth, which is a simple function of their productivity

$$
R(z)= \begin{cases}1+r, & z<\hat{z} \\ \frac{(\varrho z-r-\delta)}{(1-\theta)}+1+r, & z \geq \hat{z}\end{cases}
$$

Given these definitions, the budget constraint of entrepreneur $j$, with net worth $a_{t}^{j}$ and with a cash-in-advance constraint.

${ }^{10}$ This property allows for a tight characterization of the evolution of aggregate variables. 
productivity $z^{j}$, will be given by

$$
c_{1 t}^{j}+c_{2 t}^{j}+a_{t+1}^{i}+\frac{m_{t+1}^{j}}{p_{t}}=R_{t}\left(z^{j}\right) a_{t}^{j}+\frac{m_{t}^{j}}{p_{t}}-T_{t}^{e},
$$

where we assume that lump-sum taxes (transfers if negative) do not depend on the productivity of entrepreneurs. ${ }^{11}$

These budget constraints imply that agents choose, at $t$, money balances $m_{t+1}^{i}$ for next period, as the cash-in-advance constraints (2) make clear. Thus, we are adopting the timing convention of Svensson (1985), in which agents buy cash goods at time $t$ with the money holdings they acquired at the end of period $t-1 .^{12}$

Workers There is a mass $L$ of identical workers, endowed with a unit of time each period that they inelastically supply to the labor market. Thus, their budget constraints are given by

$$
c_{1 t}^{W}+c_{2 t}^{W}+a_{t+1}^{W}+\frac{m_{t+1}^{W}}{p_{t}}=\left(1+r_{t}\right) a_{t}^{W}+w_{t}+\frac{m_{t}^{W}}{p_{t}}-T_{t}^{W},
$$

where $a_{t+1}^{W}$ and $m_{t+1}^{W}$ are real financial assets and nominal money holdings chosen at time $t$ and $T_{t}^{W}$ are lump-sum taxes. We impose on workers a non borrowing constraint, so $a_{t}^{W} \geq 0$ for all $t .^{13}$

\subsection{Optimality Conditions}

The optimal problem of agents is to maximize (1) subject to (2) and (4) for entrepreneurs or (5) for workers. To save on notation, we drop the index for individual entrepreneurs $j$ unless strictly necessary.

We first briefly explain the zero bound equilibrium restriction on the nominal interest rate that arises from the agent's optimization problem because this is a key aspect of the model. We then discuss the other first-order conditions.

\footnotetext{
${ }^{11}$ Note that it is efficient to transfer resources from low productivity entrepreneurs to high productivity ones. This can be achieved by productivity-specific taxes. Given the exogenous nature of the collateral constraints, we do not find those policies interesting.

${ }^{12} \mathrm{An}$ advantage of this timing is that it treats all asset accumulation decisions symmetrically, using the standard timing from capital theory, where production by entrepreneurs at time $t$ is done with capital goods accumulated at the end of period $t-1$.

${ }^{13}$ This is a natural constraint to impose. It is equivalent to impose on workers the same collateral constraints entrepreneurs face, since workers will never decide to hold capital in equilibrium.
} 
In this economy, gross savings (demand for bonds) come from inactive entrepreneurs and, potentially, from workers. Note that the return on holding financial assets for these agents is $R_{t}(z)=\left(1+r_{t}\right)$, whereas the return on holding money-ignoring the liquidity services - is given by $p_{t} / p_{t+1}$. Thus, if there is intermediation in equilibrium, it must be the case that

$$
\left(1+r_{t}\right) \frac{p_{t}}{p_{t-1}}-1 \geq 0 \text { for all } t
$$

The first-order conditions of the household's problem imply:

$$
\begin{aligned}
\frac{1}{\beta} \frac{c_{2 t+1}(z)}{c_{2 t}(z)} & =R_{t+1}(z), \quad t \geq 0 \\
\frac{\nu}{1-\nu} \frac{c_{2 t+1}(z)}{c_{1 t+1}(z)} & =R_{t+1}(z) \frac{p_{t+1}}{p_{t}}, \quad t \geq 1 .
\end{aligned}
$$

Solving forward the period budget constraint (4), using the optimal conditions (7) and (8) for all periods, and assuming that the cash-in-advance constraint is binding at the beginning of period $t=0$, we obtain the solutions for consumption of the credit good and financial assets for agents that face a strictly positive opportunity cost of money in period $t+1,{ }^{14}$

$$
\begin{aligned}
c_{2 t}(z) & =\frac{(1-\nu)(1-\beta)}{1-\nu(1-\beta)}\left[R_{t}(z) a_{t}-\sum_{j=0}^{\infty} \frac{T_{t+j}^{e}}{\prod_{s=1}^{j} R_{t+s}(z)}\right] \\
a_{t+1}(z) & =\beta\left[R_{t}(z) a_{t}-\sum_{j=0}^{\infty} \frac{T_{t+j}^{e}}{\prod_{s=1}^{j} R_{t+s}(z)}\right]+\sum_{j=1}^{\infty} \frac{T_{t+j}^{e}}{\prod_{s=1}^{j} R_{t+s}(z)} .
\end{aligned}
$$

This solution exhibits the standard property implied by log-utility: consumption is proportional to current wealth, which is equal to the current value of the assets minus the present value of taxes, the term in brackets on the right-hand side of the consumption equation. The counterpart of the proportionality of consumption is the constant savings rate once the provision for future taxes is taken into account - the second term on the right hand side of the wealth equation. These properties are key to being able to write the law of motion for macroeconomic aggregates in Section 3 below.

\footnotetext{
${ }^{14}$ Note that it could be possible that initial money holdings are so large for an active entrepreneur that the cash-in-advance constraint will not be binding in the first period. This case will not be relevant provided initial real cash balances are not too big.
} 
Note that future taxes are discounted using type-specific rates of return. These rates of return are the same as the real interest rate on government bonds for inactive entrepreneurs, but they are higher for active entrepreneurs.

We will use type-specific discounted sums as in (9) several times in what follows. To simplify the expressions, we define

$$
\prod_{s=1}^{j} R_{t+s}(z)=Q_{t+j}(z) \text { and } \prod_{s=1}^{j}\left(1+r_{t+s}\right)=q_{t+j}
$$

where the first variable is agent specific and the second discounts using the real interest rate.

These equations always characterize the solution for active entrepreneurs even when nominal interest rates are zero. The reason is that for them, the opportunity cost of holding money is given by $R_{t}(z) p_{t+1} / p_{t}>\left(1+r_{t}\right) p_{t+1} / p_{t} \geq 1$, where the last inequality follows form (6). The solution also characterizes the optimal behavior of inactive entrepreneurs, as long as $\left(1+r_{t}\right) p_{t+1} / p_{t}-1>0$.

The solution for inactive entrepreneurs in periods in which the nominal interest rate is zero, $\left(1+r_{t}\right) p_{t+1} / p_{t}-1=0$, is

$$
a_{t+1}(z)+\frac{m_{t+1}(z)}{p_{t}}-\frac{m_{t+1}^{T}(z)}{p_{t}}=\beta\left[R_{t}(z) a_{t}-\sum_{j=0}^{\infty} \frac{T_{t+j}^{e}}{Q_{t+j}(z)}\right]+\sum_{j=1}^{\infty} \frac{T_{t+j}^{e}}{Q_{t+j}(z)}
$$

where

$$
\frac{m_{t+1}^{T}(z)}{p_{t}}=\frac{\nu(1-\beta) \beta}{1-\nu(1-\beta)}\left[R_{t}(z) a_{t}-\sum_{j=0}^{\infty} \frac{T_{t+j}^{e}}{Q_{t+j}(z)}\right]
$$

are the real money balances that will be used for transaction purposes in period $t+1$. Thus, $m_{t+1} / p_{t}-m_{t+1}^{T} / p_{t} \geq 0$ are the excess real money balances, hoarded from period $t$ to $t+1$.

The optimal plan for workers is slightly more involved because their income is nonhomogeneous in their net worth and they will tend to face binding borrowing constraints in finite time. In particular, as long as the $\left(1+r_{\infty}\right) \beta<1$, as will be the case in the equilibria we will discuss, where $r_{\infty}$ is the real interest rate in the steady state, workers drive their wealth to zero in finite time and are effectively hand-to-mouth consumers 
in the long run. That is, for sufficiently large $t$,

$$
c_{2, t}^{W}=\frac{(1-\nu)\left(w_{t}-T_{t}^{W}\right)}{1-\nu(1-\beta)} \text { and } c_{1, t+1}^{W}=\frac{m_{t+1}^{W}}{p_{t+1}}=\frac{\nu\left(w_{t}-T_{t}^{W}\right)}{1-\nu(1-\beta)} \frac{\beta p_{t}}{p_{t+1}} .
$$

Along a transition, workers may accumulate assets for a finite number of periods. This would typically be the case if they expect a future drop in their wages - as in the credit crunch we consider - or if they receive a temporarily large transfer, $T_{t}^{W}<0$.

\subsection{Demographics}

Relative to the model in Moll (2014), we assumed that the productivity types are permanent. To guarantee that there is a non degenerated distribution of wealth shares across productivity types in the stationary equilibrium, we assume a stochastic lifecycle structure without annuities markets. ${ }^{15}$

Specifically, we assume that a fraction $1-\gamma$ of entrepreneurs depart for Nirvana every period and are replaced by an equal number of new entrepreneurs. The productivity $z$ of the new entrepreneurs is drawn from the same distribution $\Psi(z)$, i.i.d. across entrepreneurs and over time. There are no annuity markets, so each new entrepreneur inherits the assets of a randomly drawn departed entrepreneur. Agents do not care about future generations, so if we let $\hat{\beta}$ be the pure discounting factor, they discount the future with the compound factor $\beta=\hat{\beta} \gamma$, which is the one we used above.

\subsection{The Government}

In every period, the government chooses the money supply $M_{t+1}$, issues one-period bonds $B_{t+1}$, and uses type-specific lump-sum taxes (subsidies) $T_{t}^{e}$ and $T_{t}^{W}$. Government policies are constrained by a sequence of period-by-period budget constraints:

$$
B_{t+1}-\left(1+r_{t}\right) B_{t}+\frac{M_{t+1}}{p_{t}}-\frac{M_{t}}{p_{t}}+T_{t}^{e}+L T_{t}^{W}=0, \quad t \geq 0 .
$$

\footnotetext{
${ }^{15}$ These alternative assumptions allow us to obtain simple closed-form expressions for the policy functions of entrepreneurs in the presence of lump-sum taxes, which are useful to illustrate the effect of alternative monetary and fiscal policies.
} 


\section{Equilibrium}

Given policies $\left\{M_{t}, B_{t}, T_{t}^{e}, T_{t}^{W}\right\}_{t=0}^{\infty}$ and collateral constraints $\left\{\theta_{t}\right\}_{t=0}^{\infty}$, an equilibrium is given by prices $\left\{r_{t}, w_{t}, p_{t}\right\}_{t=0}^{\infty}$ and corresponding quantities such that:

- Entrepreneurs and workers maximize their utility, taking as given prices and policies,

- The government budget constraint is satisfied, and

- Bond, labor, and money markets clear:

$$
\int b_{t+1}^{j} d j+L b_{t}^{W}+B_{t+1}=0, \quad \int l_{t}^{j} d j=L, \quad \int m_{t}^{j} d j+L m_{t}^{W}=M_{t}, \quad \text { for all } t .
$$

To illustrate the mechanics of the model, we first provide a partial characterization of the equilibrium dynamics of the economy for the case in which the zero lower bound is never binding, $1+r_{t+1}>p_{t} / p_{t+1}$ for all $t$, workers are hand to mouth, $a_{t}^{W}=0$ and pay no taxes $T_{t}^{w}=0$ for all $t$, and the share of cash goods is arbitrarily small, $\nu \approx 0$. Second, we discuss some properties of the model when the zero bound constraint binds. Finally, we study a very special case for which we can obtain closed-form solutions.

\subsection{Equilibrium Away from the Zero Bound}

The state of the economy at any point in time is given by the capital stock $K_{t}$, the measure of wealth $\Phi_{t}(z)$, and the cutoff $\hat{z}_{t}$. We now show how the equilibrium conditions determine the new values of these three objects.

First, note that integrating the production function of all active entrepreneurs, equilibrium output is given by a Cobb-Douglas function of aggregate capital $K_{t}$, aggregate labor $L$, and aggregate productivity $Z_{t}$,

$$
Y_{t}=Z_{t} K_{t}^{\alpha} L^{1-\alpha}
$$

where aggregate productivity is given by the wealth-weighted average of the productivity of active entrepreneurs, $z \geq \hat{z}_{t}$,

$$
Z_{t}=\left(\frac{\int_{\hat{z}_{t}}^{\infty} z \Phi_{t}(d z)}{\int_{\hat{z}_{t}}^{\infty} \Phi_{t}(d z)}\right)^{\alpha}
$$


The higher the wealth of the high productivity entrepreneur, the larger their relative size and the higher is aggregate TFP. Note also that $Z_{t}$ is an increasing function of the cutoff $\hat{z}_{t}$.

To obtain the evolution of aggregate capital, we integrate over the individual optimal saving decisions of entrepreneurs and use market clearing conditions. Because of the proportional optimal decision rules obtained in (9), this results in a linear function of aggregate output, the initial capital stock, and the aggregate of the (individual-specific) present value of taxes,

$$
\begin{aligned}
K_{t+1}+B_{t+1}= & \beta\left[\alpha Y_{t}+(1-\delta) K_{t}+\left(1+r_{t}\right) B_{t}-\int_{0}^{\infty} \sum_{j=0}^{\infty} \frac{T_{t+j}^{e}}{Q_{t+j}(z)} \Psi(d z)\right] \\
& +\int_{0}^{\infty} \sum_{j=1}^{\infty} \frac{T_{t+j}^{e}}{Q_{t+j}(z)}(d z) .
\end{aligned}
$$

Note that the first period of the sum in brackets on the right-hand side is zero, whereas the first term in the sum of the last term on the right-hand side is one. We can then use the term corresponding to $j=0$ of the sum that is inside the brackets and subtract it from the value of the debt $\left(1+r_{t}\right) B_{t}$. We can then solve forward the government budget constraint (11), using that $\nu \approx 0$, and replace the term $\left(1+r_{t}\right) B_{t}-$ $T_{t}^{e}$ and substitute it into (14) to obtain

$$
K_{t+1}=\beta\left[\alpha Y_{t}+(1-\delta) K_{t}\right]+(1-\beta) \int_{0}^{\infty} \sum_{j=1}^{\infty} T_{t+j}^{e}\left[\frac{1}{Q_{t+j}(z)}-\frac{1}{q_{t+j}}\right] \Psi(d z)
$$

The first term gives the evolution of aggregate capital in an economy without taxes. In this case, aggregate capital in period $t+1$ is a linear function of aggregate output and the initial level of aggregate capital. The second term captures the departure from Ricardian equivalence. For example, imagine a case in which there is positive debt and taxes are positive every period, equal to the interest payments. Since $Q_{t+j}(z)>q_{t+j}$ for all $z>\widehat{z}$, the second term is negative, reflecting the fact that public debt crowds out private investment and results in lower aggregate capital next period. 
Given the capital stock at $t+1$, the evolution of the wealth measure is given by

$$
\begin{aligned}
\Phi_{t+1}(z)= & \gamma\left[\beta\left[R_{t}(z) \Phi_{t}(z)-\sum_{j=0}^{\infty} \frac{T_{t+j}^{e} \Psi(z)}{Q_{t+j}(z)}\right]+\sum_{j=1}^{\infty} \frac{T_{t+j}^{e} \Psi(z)}{Q_{t+j}(z)}\right] \\
& +(1-\gamma) \Psi(z)\left(K_{t+1}+B_{t+1}\right)
\end{aligned}
$$

where the first term on the right-hand side reflects the decision rules of the $\gamma$ fraction of entrepreneurs that remain alive, and the second reflects the exogenous allocation of the assets of departed entrepreneurs among the new generation.

Then, given the (exogenous) value for $\theta_{t+1}$ and the wealth measure $\Phi_{t+1}(z)$, the cutoff for next period is determined by the bond market clearing condition

$$
\int_{0}^{\hat{z}_{t+1}} \Phi_{t+1}(d z)=\frac{\theta_{t+1}}{1-\theta_{t+1}} \int_{\hat{z}_{t+1}}^{\infty} \Phi_{t+1}(d z)+B_{t+1} .
$$

The left-hand side is total wealth of inactive entrepreneurs or, equivalently, the total supply of funds because we assumed workers to be hand to mouth. The first term on the right-hand side is total private demand for funds, which is equal to the leverage times the wealth of active entrepreneurs. The second term is government net demand for funds.

Finally, we describe the determination of the price level. In the previous derivations, in particular, to obtain (15) and (16), we have used that $\nu \approx 0$, and therefore, the money market clearing condition is not necessarily well defined. ${ }^{16}$ More generally, given monetary and fiscal policy, the price level is given by the equilibrium condition in the money market, for $t \geq 0$,

$$
\begin{array}{r}
\frac{M_{t+1}}{p_{t}}=\frac{\nu(1-\beta) \beta}{1-\nu(1-\beta)}\left[\alpha Y_{t}\right. \\
+(1-\delta) K_{t}+\left(1+r_{t}\right) B_{t} \\
\left.\quad-\int_{0}^{\infty} \sum_{j=0}^{\infty} \frac{T_{t+j}^{e}}{Q_{t+j}(z)} \Psi(d z)\right]
\end{array}
$$

The nominal interest rate is obtained from the inter temporal condition of inactive entrepreneurs,

\footnotetext{
${ }^{16}$ To determine the price level in the cashless limit, we let $M_{t+1}, \nu \rightarrow 0, M_{t+1} / \nu \rightarrow \tilde{M}_{t+1}>0$. See details in Section 3.3.3.
} 


$$
\frac{1}{\beta} \frac{c_{2 t+1}}{c_{2 t}}=\frac{1+i_{t+1}}{\frac{p_{t+1}}{p_{t}}}=1+r_{t+1}, \text { for } t \geq 0
$$

Note that, except for the well-known Sargent-Wallace initial price level indeterminacy result, we can think of monetary policy as sequences of money supplies, $\left\{M_{t}\right\}_{t=0}^{\infty}$, or sequences of nominal interest rates, $\left\{i_{t}\right\}_{t=0}^{\infty}$. We will think of policy as determining exogenously one of the two sequences, abstracting from the implementability problem. ${ }^{17}$

There are two important margins in this economy. The first is the allocation of capital across entrepreneurs, which is dictated by the collateral constraints and which determines measured TFP (see (13)). The second is the evolution of aggregate capital over time, which, in the absence of taxes, behaves as in Solow's model (see (15) and set $\left.T_{t+j}^{e}=T_{t+j}^{W}=0\right)$. Clearly, fiscal policy has aggregate implications: the net supply of bonds affects (17) and taxes affect (15). However, monetary policy does not, because none of those equations depend on nominal variables. Monetary policy does have effects, because it distorts the margin between cash and credit goods, but in a fashion that resembles the effects of monetary policy in a representative agent economy. This is the case only if, as assumed above, the zero bound does not bind.

\subsection{Equilibrium at the Zero Bound}

In periods in which the zero bound binds, successful inflation-targeting policies will affect equilibrium quantities if the target for inflation is tight enough. By successfully controlling inflation, monetary and debt policy, together with the zero bound on nominal interest rates, can impose a bound on real interest rates. To see this, use (19) and the zero bound to write

$$
1+i_{t}=\frac{p_{t}}{p_{t-1}}\left(1+r_{t}\right) \geq 1, \text { so } r_{t} \geq \frac{p_{t-1}-p_{t}}{p_{t}}=-\left(\frac{\pi_{t}}{1+\pi_{t}}\right)
$$

where $\pi_{t}$ is the inflation rate.

Imagine now an economy with zero net supply of bonds that enters a credit crunch, generated by a drop in $\theta_{t}$. Equation (17) implies that the threshold $\hat{z}_{t+1}$ has to go down to reduce the left-hand side and increase the right-hand side so as to restore the equilibrium. This drop in the gross supply of private bonds will reduce the real interest

\footnotetext{
${ }^{17}$ Because we use log utility, there is a unique solution for prices, given the sequence $\left\{M_{t}\right\}_{t=0}^{\infty}$.
} 
rate, so the marginal entrepreneurs that were lending capital now start borrowing until market equilibrium is restored (i.e., the net supply of bonds is zero). If the credit crunch is large enough, the equilibrium real interest rate may become negative. If inflation is not high enough, the bound (20) may be binding. Imagine, for instance, the case of inflation targeting with a target equal to zero.

If the target for inflation were indeed zero and a credit crunch would bring, in the absence of policy, the real interest rate to negative values, equation (20) would be violated. One possible equilibrium has inflation positive enough to satisfy the bound, but the target would not be achieved. But there is a policy that induces an equilibrium where the target is satisfied. To support the zero inflation policy, the government must inject enough liquidity so that the net supply of money (or bonds, since they are perfect substitutes at the zero bound) goes up to the point where conditions (17) and (20) are jointly satisfied. In other words, there must be a large enough injection of liquidity to partially compensate for the effect of the credit crunch on the real interest rate and such that it prevents the real rate to fall below zero.

This policy will have implications for the equilibrium cutoff $\hat{z}_{t+1}$. In addition, as can be seen in (14), the injection of liquidity (increases in $B_{t+1}$ ) affects capital accumulation. Thus, at the zero bound, the level of inflation chosen by the central bank, if low enough, can affect the two relevant margins in the economy. To further explore these implications in this general model, we need to solve it numerically. But before doing that, we now present a particular (very special) case that can be analytically solved and analyzed, which we find useful in isolating and understanding some of the mechanisms of the model.

\subsection{A Simple Case with a Closed-Form Solution}

An interesting feature of the model is the interaction between the credit constraints and the endogenous savings decisions. This interaction generates dynamics that imply longrun effects that are very different from the ones obtained on impact, precisely through the endogenous decisions agents make over time to save away from those constraints. A complication is that the endogenous wealth distribution becomes a relevant state variable, and it becomes impossible to obtain analytical results.

It is possible, however, to obtain closed-form solutions if we shut down that endogenous evolution of the wealth distribution. Some of the effects that the simulations

of the general model exhibit are also present in this simplified version, where they are 
easier to understand. We now proceed to discuss that example.

Consider the case in which $\gamma \rightarrow 0$ but $\hat{\beta} \rightarrow \infty$, such that $\beta=\hat{\beta} \gamma$ is kept constant. In this limit, agents live for only a period, but the saving decisions are not modified, so equation (16) becomes

$$
\Phi_{t+1}(z)=\Psi(z)\left(K_{t+1}+B_{t+1}\right) .
$$

We also let $z$ be uniform in $[0,1]$. Then, the equilibrium condition for the credit market (17) and the value of TFP in equation (13) become

$$
\hat{z}_{t+1}=\theta_{t+1}+\left(1-\theta_{t+1}\right) b_{t+1} \text { and } Z_{t}=\left(\frac{1+\theta_{t}+\left(1-\theta_{t}\right) b_{t}}{2}\right)^{\alpha}
$$

where $b_{t}=\frac{B_{t}}{K_{t}+B_{t}}$. In addition, we set $L=1$ so the law of motion for capital (15) becomes

$$
\begin{aligned}
K_{t+1}= & \beta\left[\alpha\left(\frac{1+\theta_{t}+\left(1-\theta_{t}\right) b_{t}}{2}\right)^{\alpha} K_{t}^{\alpha}+(1-\delta) K_{t}\right] \\
& +(1-\beta)\left[\int_{0}^{\infty} \sum_{j=1}^{\infty} \frac{T_{t+j}^{e}}{Q_{t+j}(z)} d z-B_{t+1}\right] .
\end{aligned}
$$

Note that given sequences of policies and collateral constraints, this equation fully describes the dynamics of capital.

The economy behaves as it does in Solow's growth model, except that the collateral constraint as well as the fiscal policy both matter. The collateral constraint matters because it affects aggregate TFP. Lump-sum taxes matter because the model does not exhibit Ricardian equivalence.

Finally, the real interest rate is given by

$$
\delta+r_{t+1}=\alpha \frac{\theta_{t+1}+\left(1-\theta_{t+1}\right) b_{t+1}}{Z_{t+1}^{\frac{1-\alpha}{\alpha}} K_{t+1}^{1-\alpha}} .
$$

In addition, the constraint (20) must be satisfied.

To gain understanding of some of the effects on equilibrium outcomes of changes in the collateral constraint and of the effects of monetary and fiscal policy, we now solve several simple exercises. In the first two exercises, we solve for the real economy, where $\nu=0$, and focus the discussion on the evolution of real variables. 
We first set all transfers to zero and study the effect of a credit crunch: an anticipated drop in $\theta_{t}$ that lasts one period and then goes back to its steady state value. ${ }^{18}$ We show that total factor productivity, output, and capital accumulation drop, so the effect of output is persistent. We also show that the real interest rate goes down. These results are all special cases of Buera and Moll (2015).

We then keep $\theta_{t}$ constant and study the effect of debt-financed transfers to show the effect of an increase in the outside supply of bonds in the equilibrium. We show that debt issuance crowds out private investment but increases total factor productivity, so the effect on output is ambiguous. In addition, debt issuance increases the real interest rate.

Finally, we consider the cashless limit and study the behavior of the price level following a credit crunch where the real interest rate becomes negative and the zero bound on the nominal interest rate becomes binding. We show that if the central bank does not change the nominal quantity of money, a deflation follows.

\subsubsection{The Effect of a Credit Crunch: Buera and Moll (2015)}

We model a temporary credit crunch by setting $\theta_{0}=\theta^{s s}, \theta_{1}=\theta_{l}<\theta^{s s}$, and $\theta_{t}=\theta^{s s}$ for $t \geq 2$. To isolate the effect of a drop in $\theta$, we set $b_{t}=0$ and $T_{t}^{e}=T_{t}^{w}=0$. It follows from (21) that TFP goes down at $t=1$ during the credit crunch. Given the level of capital, the interest rate is given by

$$
\delta+r_{t}=\frac{\theta_{t}}{\left(1+\theta_{t}\right)^{1-\alpha}} \frac{2^{1-\alpha} \alpha}{K_{t}^{1-\alpha}}
$$

which implies that the real interest rate falls with $\theta_{t}$. This drop in the real interest rate is what provides incentives to the less efficient entrepreneurs to enter until the credit market clears, thereby reducing TFP. ${ }^{19}$ Note that the real interest rate will be negative if $\theta_{l}$ is low enough. We find this feature of the model particularly attractive in studying the Great Recession: a single shock can explain both the gap between output and trend and the negative real interest rates.

The law of motion for capital is given by.

\footnotetext{
${ }^{18}$ Nothing important hinges on the credit crunch lasting one single period. It only makes the algebra simpler.

${ }^{19}$ The drop in the real interest rate as the collateral constraint falls enough is a general feature of the model, which does not depend on the particular simplifying assumptions used in this example. In general, $r_{t}=\hat{z}_{t} / \mathbf{E}\left[z \mid z \geq \hat{z}_{t}\right]^{1-\alpha} K_{t}^{\alpha-1}-\delta$, which tends to $-\delta$ as $\theta_{t}$ - and therefore $\hat{z}_{t}$ - converges to zero.
} 


$$
K_{t+1}=\beta\left[\alpha\left(\frac{1+\theta_{t}}{2}\right)^{\alpha} K_{t}^{\alpha}+(1-\delta) K_{t}\right]
$$

The effect on capital is identical to a temporary drop in TFP in Solow's model: capital does not change on impact, but goes down at $t=1$. Then, it starts going up to the steady state.

\subsubsection{The Effect of Policy}

We consider the case in which there are no taxes or transfers to workers $\left(\right.$ so $\left.T_{t}^{w}=0\right) .{ }^{20}$ First, note that (21) implies that total factor productivity is increasing in the ratio of debt to total assets. We now show that it also crowds out investment.

Assume that the economy starts at the steady state and consider the policy

$$
B_{0}=0, \quad B_{1}=-T_{0}=B>0 \text { and }\left(1+r_{1}\right) T_{0}+T_{1}=0
$$

so $B_{t}=0$ for $t \geq 2$. Thus, at time 0 there is a deficit (a transfer to all entrepreneurs) financed by issuing debt. Then, at time 1, there is a surplus (a tax on all entrepreneurs) that is enough to pay off all bonds issued at time 0 .

Given this policy, the law of motion for capital (22) becomes

$$
K_{1}=K_{s s}-(1-\beta) B\left[1-\int_{0}^{1} \frac{\left(1+r_{1}\right)}{R_{1}(z)} d z\right]
$$

Without collateral constraints, or $\theta=1, R_{1}(z)=\left(1+r_{1}\right)$ for all $z$ (and $\hat{z}=1$ ), so the term in brackets on the right-hand side becomes zero which implies $K_{1}=K_{s s}$ : Ricardian equivalence holds. But when $\theta \in(0,1)$, from $(3)$ it follows that $R_{1}(z)>$ $\left(1+r_{1}\right)$ for $z>\hat{z}$ (and $\left.\hat{z} \in(0,1)\right)$, and then

$$
0<\int_{0}^{1} \frac{\left(1+r_{1}\right)}{R_{1}(z)} d z=\hat{z}+\int_{\hat{z}}^{1} \frac{\left(1+r_{1}\right)}{R_{1}(z)}<1 .
$$

Thus, the level of capital is lower than the steady state for any positive level of debt.

Thus, starting at $B=0$, as debt increases, total factor productivity goes up, as seen

\footnotetext{
${ }^{20}$ We solve the case in which workers are also taxed in the Online Appendix, Section B, where, to keep analytical tractability, we also assume that workers are hand to mouth. In our simulations, we solve for the general case in which workers can hold bonds.
} 
from (21), but capital goes down, so the net effect on output is ambiguous. ${ }^{21}$ Finally, note that the interest rate on period 1 is given by

$$
\delta+r_{1}=\frac{\theta+b_{1}(1-\theta)}{\left(1+\theta+b_{1}(1-\theta)\right)^{1-\alpha}} \frac{\alpha 2^{1-\alpha}}{K_{1}^{1-\alpha}},
$$

where the first term is increasing on $b_{1}$, so the interest rate will be higher than in the steady state.

To summarize, a credit crunch and an increase in debt have opposite effects on total factor productivity and on the real interest rate: whereas the credit crunch reduces both, an increase in debt increases both. On the other hand, the credit crunch and the debt increase reinforce each other in that they reduce capital accumulation.

As increases in outside liquidity (bonds plus money at the zero bound) dampen the drop in the real interest rate, they will be effective at achieving a target for inflation when the zero bound binds. Doing so also implies a lower drop in TFP (a higher threshold) but a larger drop in capital. The net effect on output is in general ambiguous, but it can be shown to be positive in the neighborhood of $B=0 .{ }^{22}$

This trade-off will be present in our simulations of the general model that allows for rich dynamics of the wealth distribution and uses alternative functional forms for the distribution of $z$.

\subsubsection{Deflation Follows Passive Policy}

We want to discuss the behavior of the price level following a credit crunch such that the zero bound constraint binds given a constant money supply. As before, we maintain the net supply of bonds equal to zero, so there are no taxes or transfers in any period.

Given the one-period credit crunch considered and under certain assumptions regarding parameters, the zero bound is binding for only one period, so $i_{1}=0$, but $i_{t}>0$ for all $t \geq 2 .{ }^{23}$ In addition, we focus on the cashless limit case, because the real allocation does not depend on the evolution of the price level. If this were not the case, there would be an interaction between nominal and real variables, and we could not

\footnotetext{
${ }^{21}$ The relationship between government debt and aggregate capital is non monotonic. In particular, one can show that as $B \rightarrow \infty$, aggregate capital converges to the steady state value in an economy with $\theta=1$.

${ }^{22}$ The analysis of the net effect on output is presented in the Online Appendix, Section B.

${ }^{23}$ Nothing relevant changes if the nominal interest is zero for more periods, but the characterization is simpler in this case. We will assume that parameters satisfy those properties.
} 
obtain closed-form solutions. ${ }^{24}$ Under these conditions, we then explain why deflation would follow a credit crunch if policy does not respond.

The cashless limit We consider the limiting case of the cashless economy (i.e., $\nu \rightarrow 0$ ). In taking the limit, though, we also let nominal money balances shrink at the same rate, so we can still meaningfully determine the equilibrium price level. The details follow.

When the cash-in-advance constraint is binding, the first-order condition (8) is

$$
p_{t} c_{t}^{1}(z)=\frac{\nu}{1-\nu} c_{t}^{2}(z) p_{t-1} \frac{1}{R_{t}(z)} .
$$

We define $\bar{m}_{t}(z)=\frac{m_{t}(z)}{\nu}$, so $p_{t} c_{t}^{1}(z)=m_{t}(z)=\bar{m}_{t}(z) \nu$. Replacing this condition on the equation above and taking the limit when $\nu \rightarrow 0$, we obtain

$$
\bar{m}_{t}(z)=c_{t}^{2}(z) p_{t-1} \frac{1}{R_{t}(z)}
$$

Finally, using the optimal rule for the credit good (9), specialized for the limiting case

$$
c_{t}^{2}(z)=(1-\beta) R_{t}(z) k_{t}(z)
$$

and aggregating over all agents, we obtain

$$
\bar{M}_{t}=(1-\beta) K_{t} p_{t-1}
$$

where $\bar{M}_{t}=\frac{M_{t}}{\nu}$ represents aggregate money balances relative to the preference parameter $\nu$. This equation determines the price level in the economy.

Because of the cashless limit and since debt and transfers are all zero, the real variables follow the solution described in (24) and (23), irrespectively of the evolution of the price level.

As we mentioned, we will consider a configuration of parameters such that the real interest rate is positive in the steady state, becomes negative at time 1 during the

\footnotetext{
${ }^{24}$ In the general case, non negligible money balances crowd out capital and ameliorate the drop in the real interest rate and in total factor productivity.
} 
credit crunch, and becomes positive again from time 2 onward. Thus, we assume that

$$
\frac{2 \theta_{s s}}{\left(1+\theta_{s s}\right)}>\beta
$$

which implies that the real interest rate is positive in the steady state. ${ }^{25}$ During the credit crunch, at $t=1$ the real interest rate is

$$
r_{1}=(\rho+\delta) \frac{2 \theta_{l}}{\left(1+\theta_{l}\right)}\left(\frac{1+\theta_{l}}{1+\theta_{s s}}\right)^{\alpha}-\delta
$$

which is negative as long as

$$
\frac{2 \theta_{l}}{\left(1+\theta_{l}\right)}\left(\frac{1+\theta_{l}}{1+\theta_{s s}}\right)^{\alpha}<\frac{\delta}{(\rho+\delta)} \text {. }
$$

Clearly, there exists a value for $\theta_{l} \in\left(0, \theta_{s s}\right)$ such that this constraint is satisfied. As $\theta_{t}=\theta_{s s}$ for $t \geq 2$, the real interest rate becomes positive from time 2 onward.

The conditions that determine the price level Since we assume that policy is passive, we let $\bar{M}_{t+1}=\bar{M}$. Using (26), we obtain that

$$
1+i_{t}=\left(1+r_{t}\right) \frac{p_{t}}{p_{t-1}}=\left(1+r_{t}\right) \frac{K_{t}}{K_{t+1}} \text { for all } t \geq 2 .
$$

From $t=2$ onward, the real interest rate is positive, but there is deflation: capital is growing back to the steady state. It is possible to show, however, that under assumption (27), the deflation is not enough to make the nominal interest rate zero from time 2 onward.

Lemma 1: Given assumption (27), $i_{t}>0$ for $t \geq 2$.

Proof: See Online Appendix, Section A.

\footnotetext{
${ }^{25}$ The necessary condition for positive interest rates in the steady state, $\frac{2 \theta_{s s}}{\left(1+\theta_{s s}\right)}>\frac{\delta}{\rho+\delta}$, is weaker. The stronger condition that we assume will also imply that the zero bound on nominal interest rates binds one period at most and simplifies the example.
} 
The previous lemma implies that

$$
p_{t}=\frac{\bar{M}}{(1-\beta) K_{t+1}} \text { for } t \geq 1 \text {. }
$$

We now show that under certain conditions on the parameters, the zero bound is binding at $t=1$.

Assume, toward a contradiction, that $i_{1}>0$. Then, the price level and the inflation rate at time zero are given by

$$
\bar{M}=(1-\beta) K_{1} p_{0} \text { and } \frac{p_{1}}{p_{0}}=\frac{K_{1}}{K_{2}}
$$

and the solution for $i_{1}$ is given by

$$
1+i_{1}=\left(1+r_{1}\right) \frac{p_{1}}{p_{0}}=\left[\frac{2 \theta_{l}}{\left(1+\theta_{l}\right)}\left(\frac{1+\theta_{l}}{1+\theta_{s s}}\right)^{\alpha}(\rho+\delta)+(1-\delta)\right] \frac{K_{1}}{K_{2}} .
$$

Using the law of motion for capital (24), we have

$$
1+i_{1}=\left[\frac{2 \theta_{l}}{\left(1+\theta_{l}\right)}\left(\frac{1+\theta_{l}}{1+\theta_{s s}}\right)^{\alpha}(\rho+\delta)+(1-\delta)\right]\left[\frac{\alpha\left(\frac{1+\theta_{s s}}{2}\right)^{\alpha}+(1-\delta) K_{s s}^{1-\alpha}}{\alpha\left(\frac{1+\theta_{l}}{2}\right)^{\alpha}+(1-\delta) K_{s s}^{1-\alpha}}\right] .
$$

Because the $r_{1}$ is negative, it is clear that the first term on brackets in the right-hand side is less than one. However, because $\theta_{l}<\theta_{s s}$, the gross inflation rate, which is the second term in brackets on the right-hand side, is larger than one. To reach a contradiction (so the zero lower bound binds at time 1), it must be the case that the first term effect dominates.

As it turns out, if the rate of depreciation $\delta$ is higher than the discount rate in preferences $\rho$, the real interest rate effect dominates and the zero bound will bind at time 1. Larger values of $\delta$ make the derivative of the real interest rate with respect to $\theta_{l}$ higher than its derivative on the deflation. The technical details are provided in the following lemma.

Lemma 2: If assumption (27) holds and $\delta>\rho$, then there exists a $\tilde{\theta}_{l}>0$ such that $i_{1}=0$ for all $\theta_{l} \in\left(0, \tilde{\theta}_{l}\right]$.

Proof: See Online Appendix, Section A. 
Finally, we show that if the economy starts at the steady state, when agents learn there is a credit crunch at time zero, the equilibrium price level must be strictly below its steady state value.

Lemma 3: Under the assumptions of lemmas 1 and $2, p_{0}<p_{s s}$ for all $\theta_{l} \in\left(0, \tilde{\theta}_{l}\right)$.

Proof: The ratio of the price level at $t=0$ to the price level in the steady state $p_{s s}$ is given by

$$
\frac{p_{0}}{p_{s s}}=\left(1+r_{1}\right) \frac{p_{1}}{p_{s s}}=\left(1+r_{1}\right) \frac{K_{s s}}{K_{2}},
$$

where the second equality follows from (26) plus the fact that policy is passive, so $\bar{M}_{t}=\bar{M}$. But the law of motion (24) implies that $K_{s s}=K_{1}$, so $\frac{p_{0}}{p_{s s}}$ is equal to the right-hand side of equation (30), which, under the conditions of lemmas 1 and 2 , is lower than one.

The credit crunch drives the real interest rate below zero to the point at which the zero bound is reached. At this point, there is an excess demand for money as a "store of value." That excess demand is, of course, real rather than nominal. Because the nominal quantity is fixed by policy, the demand pressure results in deflation. The excess demand for money as a store of value will be positive until future inflation is high enough such that the return on money is as negative as the return on bonds. The initial deflation allows for future inflation along the path, required for the arbitrage condition to hold, with zero "long-run" inflation. This zero-long run inflation is the natural consequence of a constant nominal money supply.

\section{Calibration and Evaluation of the model}

In this section we first calibrate the model to the US economy and discuss how we take the model to the data. We discuss in detail the frequency we want to focus on and the way we detrend the data. Second, we numerically solve the model and compare it to the data. Finally, we perform several policy experiments to illustrate the role of policy during the Great Recession and to consider the impact of alternative policy responses. 


\subsection{Calibration}

We calibrate the model such that its steady state satisfies several conditions. There are very few parameters. We first set the capital share to be one-third and the (annual) depreciation of capital to be $7 \%$, which are standard values. We set the share of cash goods in total expenditure $\nu=0.23$ to match the share of payments (by value) done with cash by US consumers reported by Bagnall et al. (2014).

We then set the distribution of abilities to be log-normal, $z \sim \ln \mathcal{N}\left(0, \sigma_{z}\right)$, and choose the standard deviation $\sigma_{z}$ so that the log dispersion of productivity among entrepreneurs in the model matches that among manufacturing establishments in the United States, as reported by Hsieh and Klenow (2009). ${ }^{26}$ We choose the rate at which entrepreneurs exit $1-\gamma=0.10$ to match the average exit rate of US establishments from the Business Dynamics Statistics (BDS). The initial parameter of the collateral constraint, $\theta=0.69$, is chosen to match the average ratio of liabilities to non financial assets for the US non financial business sector between 1997:Q3 and 2007:Q3 ${ }^{27}$ Given the previous parameters, we set the discount factor $\beta$ equal to 0.981 , so the real interest rate is $2 \%$. Table 1 summarizes the parameter values we use. ${ }^{28}$

A key aspect of our calibration is related to the way in which fiscal policy is implemented. For the total size of government liabilities, we use the sum of money and bonds from 2007 until 2016 and assume the total remains constant thereafter, with taxes being collected to pay the interest on the debt. ${ }^{29}$ Still, because of the lack of Ricardian equivalence, there is a continuum of different ways in which the taxes and transfers can be designed so as to satisfy the observed total. And each one will imply different

\footnotetext{
${ }^{26}$ If there are diminishing returns to scale, all entrepreneurs will be active in equilibrium. Therefore, by matching the $\log$ dispersion of productivity among all entrepreneurs, active and inactive, the calibration is robust to the inclusion of arbitrarily small diminishing returns to scale.

${ }^{27}$ We measure liabilities as total liabilities in the flow of funds (FL114190005.Q+FL104190005.Q) minus the US real estate owned by foreigners (FL115114005.Q) and the foreign direct investment in the United States. (FL103192005.Q), which in the flow of funds are liabilities items for the non corporate and corporate sectors, respectively. Correspondingly, we measure non financial assets as the non financial assets in the flow of funds (FL112010005.Q+FL102010005.Q) minus the US real estate owned by foreigners (FL115114005.Q) and the foreign direct investment in the United States (FL103192005.Q).

${ }^{28} \mathrm{We}$ also need to specify the relative number of workers and entrepreneurs in the economy. We assume that workers are $25 \%$ of the population, $L /(1+L)=1 / 4$. We choose a low share of workers, who in our model choose to go against their borrowing constraint in a steady state, to limit the nonRicardian elements in the model. This number is consistent with the fraction of households with zero net liquid assets, which was $23 \%$ in the United States in 2001 (Kaplan and Violante, 2014).

${ }^{29}$ Notice that the composition between money and bonds is inessential when nominal interest rates are zero, as in the period we are considering.
} 


\begin{tabular}{ll} 
Parameters & Targets \\
\hline$\alpha=1 / 3,1-(1-\delta)^{4}=0.07$ & Standard values \\
$\nu=0.23$ & Share of payments (by value) done with cash \\
$z \sim \ln N(0,3.36)$ & Log dispersion of estab., US manuf. \\
$1-\gamma^{4}=0.10$ & Avg. exit rate of US establishments \\
$B_{0} /\left(4 Y_{0}\right)=0.62$ & Total public, federal debt in the US, 2007:Q2 \\
$\beta=0.987$ & $2 \%$ real interest rate \\
$\theta_{0}=0.69$ & Liabilities to nonfinancial assets, US nonfin. bus. \\
\hline
\end{tabular}

Table 1: Calibration, Initial Steady State

equilibrium paths. Because of the difficulty of using data to discipline these choices, we proceed by considering two simple cases, both respecting the principle that taxes and transfers can depend on agent classes (workers and entrepreneurs). In particular, we assume that transfers are given solely to entrepreneurs, active and inactive, whereas taxes are lump-sum to all agents. In Section 4.3.2, we consider the case with lump-sum transfers. This second case exhibits larger departures from Ricardian equivalence, as we discuss in detail below.

What remains to be calibrated is the evolution of the collateral constraint. To do so, we simulate the model, choosing the value of the collateral constraint for every period so as to reproduce the evolution of the real interest rate in the United States since the financial crisis. Specifically, we assume that starting at that steady state, all agents learn that the collateral constraint will tighten for several periods and that the Fed and the central government will substantially increase their liabilities (i.e., their supply of liquid assets), taking as given the future taxes and transfers. We chose the sequence $\left\{\theta_{t}\right\}_{t=0}^{\infty}$ so that the model broadly matches the evolution of the real interest rate, given the path for government liabilities.

We chose to focus on the behavior of the real interest rate in the United States following the financial crisis to calibrate the sequence $\left\{\theta_{t}\right\}_{t=0}^{\infty}$ for a couple of reasons. First, it is the reduction in $\theta_{t}$ that drives down the real interest rate. The direct theoretical relationship between the unobservable shock and the real rate makes it an attractive target for the calibration.

Second, the very long period of negative real interest rates, depicted in the left panel of Figure 1, is one of the most remarkable features of the events of the last decade and speaks to the persistence of the shock that drove the real rates below zero. The data series (dashed line) is obtained from Andrea et al. (2012), who compute it using a no-arbitrage model that jointly explains the dynamics of consumer prices as 

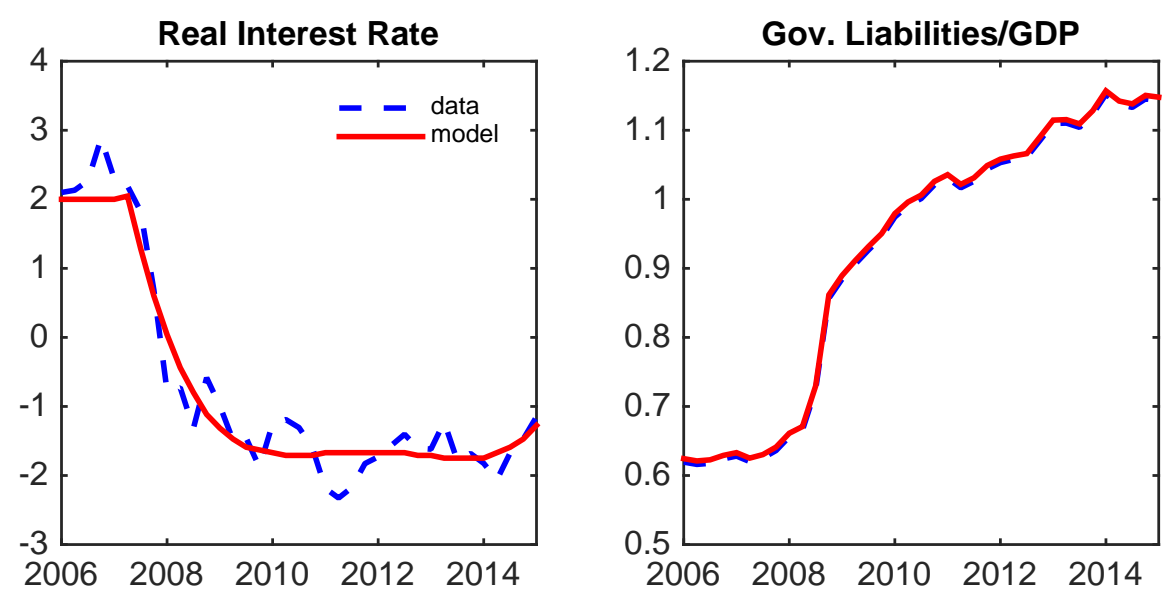

Figure 1: Real Interest Rate and Public Liquidity, Data (dashed line), and Model-Calibrated (solid line) Paths.

well as the nominal and real term structure of risk-free rates. ${ }^{30}$ The solid line, labeled "model," is a smooth version of the data reported by Andrea et al. (2012). This is our calibration target.

We use the behavior of this real rate to identify the timing, severity and persistence of the shock. As can be seen in the left panel of Figure 1, the drop in the rate is in the third quarter of 2007, so we choose this quarter as the onset of the crisis. We then chose the sequence $\theta_{t}$ such that the simulated series for the real interest rate matches the solid line in the left panel of Figure 1. The resulting calibrated shock implies that the collateral constraint, calibrated to be equal to 0.69 in the steady state, goes down sharply to 0.59 by the end of 2008 and continues a more gradual decline through 2014, where it gradually starts to go up (see the right panel of Figure 4). As mentioned before, the equilibrium does depend on the injection of total liquidity. Thus, in the simulation we also assume the total supply of outside liquidity to be the one observed in the data starting in 2007, depicted in the second panel of Figure 1. This series is the sum of the total public federal debt and the balance sheet of the Federal Reserve Banks net of their holdings of Treasury bonds. An important part of the policy response to the crisis by the Fed was to increase the supply of liquidity providing bank reserves in exchange for mortgage-backed securities. In addition, there were large tax and transfer programs that resulted in an unprecedented increase in the level of the public debt. Furthermore, we assume a path for the money supply that is

\footnotetext{
${ }^{30} \mathrm{~A}$ very similar picture emerges if one computes ex-post real rates by subtracting observed inflation from short-term nominal interest rates, (see the Working Paper version for details).
} 
consistent with an inflation rate of $2 \%$ per year in periods in which the nominal rate is strictly positive. When the nominal rate is at the zero lower bound, the inflation rate equals the negative of the real interest rate (i.e., the observed path of inflation).

\subsection{Evaluation of the Model}

We now compare the simulations of the model with the US data since the third quarter of 2007 - the date identified as the beginning of the crisis by the real interest rate until the end of our sample. In looking at variables such as output, capital, labor, or productivity, we face a difficulty that does not arise when looking at real interest rates: the trend in the data. Our model is stationary, but it can be modified to incorporate exogenous productivity growth, the same way it is done in the Solow model. To the extent that the exogenous component of productivity grows at a constant rate, allowing for this exogenous component is equivalent to removing a linear trend to the natural logarithm of the data. That is the strategy we pursue in comparing the data to the model.

In Table 2 we show the quarterly growth rate of the linear trend for the natural logarithm of output, capital, hours, and productivity using quarterly data. The linear trend has been computed by ordinary least squares regressions of the log of the corresponding variable on time. We report results for three different starting periods, 1947, 1960, and 1980. In all cases, the last period was the third quarter of 2007, the period when the crisis started according to our calibration. ${ }^{31}$

\begin{tabular}{llll} 
& \multicolumn{3}{c}{ Initial Period } \\
\cline { 2 - 4 } & $1947: \mathrm{Q} 3$ & $1960: \mathrm{Q} 1$ & $1980: \mathrm{Q} 1$ \\
\hline Output & 0.0088 & 0.0081 & 0.0080 \\
Hours & 0.0033 & 0.0042 & 0.0039 \\
Capital & 0.0092 & 0.0086 & 0.0077 \\
Productivity & 0.0027 & 0.0023 & 0.0028 \\
\hline
\end{tabular}

Table 2: Average quarterly growth of (log) GDP, hours, capital, and TFP from the specified dates and 2007:Q3.

The results are surprisingly robust to the initial date used for output and hours, but less so for capital. However, in the case of capital, the data show a clear slowdown in growth from 1960 to 1980: the linear trend does not adjust well for the first two

\footnotetext{
${ }^{31}$ See the Online Appendix, Section G and H, for details on the data sources and the computation of productivity, where we explore the effect of accounting for capacity utilization.
} 
samples. ${ }^{32}$ Thus, we choose the value for the sample that starts in 1980 . The trend for productivity also seems relatively stable, but that hides the fact that it grew very rapidly from 1947 to 1973 (a slope of 0.0043) and then remained essentially constant until 1983. It then grew at 0.0028, the rate reported for the sample that starts in 1980 .

Given this discussion, we chose the values for the trends to be the ones that result from the last period, starting in 1980, the ones reported in the last column of Table 2.
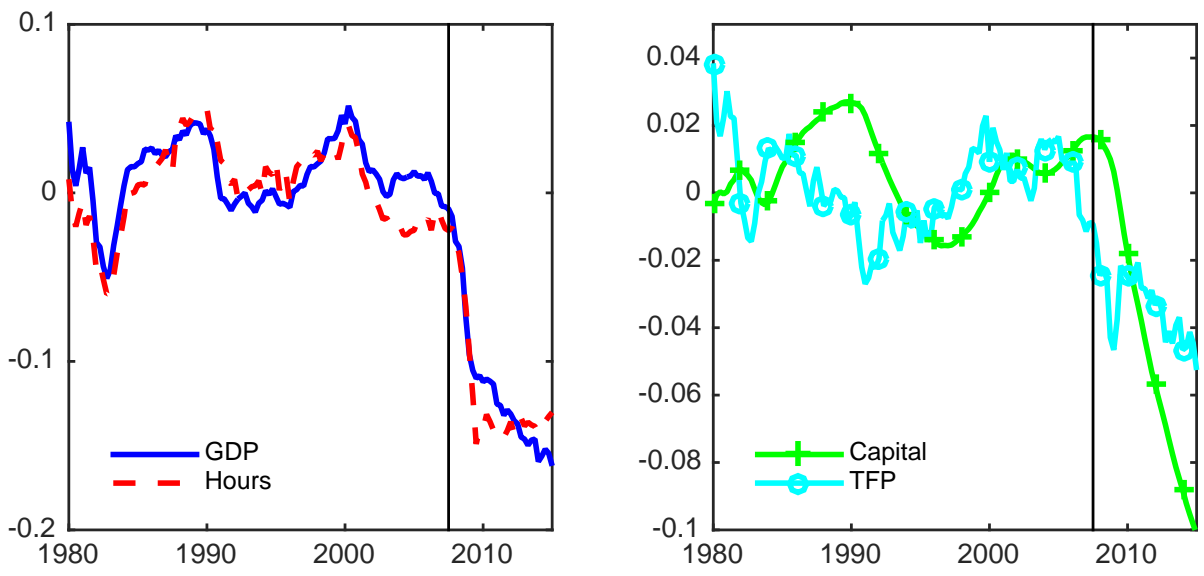

Figure 2: Detrended GDP, Hours, Capital Stock, and TFP, 1980:Q1-2015:Q1.

To show the effect of detrending in a way that makes clear the long-lasting effect of the crisis that started in 2007, in Figure 2 we depict the difference between the natural logarithm of the data and its trend (computed from 1980 to 2007) for output and hours in the left panel and for capital and productivity in the right panel. As can be seen, there are fluctuations around trend that, until 2007 never go beyond 5\% in absolute value for any of the series. However, after 2007, the deviations are all negative and much larger than anything previously seen.

We now argue that, except for hours, a relevant fraction of these changes can be accounted for by the single shock we model and that we calibrated to match the evolution of the real interest rate.

The deviations from trend shown in Figure 2 are the ones we compare to the simulation of the calibrated model. To begin with, notice that we assumed labor supply to be constant, so the model will be unable to replicate the very large drop in hours since 2007. This result would not differ if we had leisure in the utility function. As we show in the Online Appendix, Section E.2, a shock to the collateral constraint, as

\footnotetext{
${ }^{32}$ See the Online Appendix, Section G, for details on the data sources.
} 
we model it, does not have a significant quantitative effect on total hours. ${ }^{33}$ If readers were hoping to learn something meaningful regarding the relationship between credit constraints and the labor participation rate, they should stop reading now.
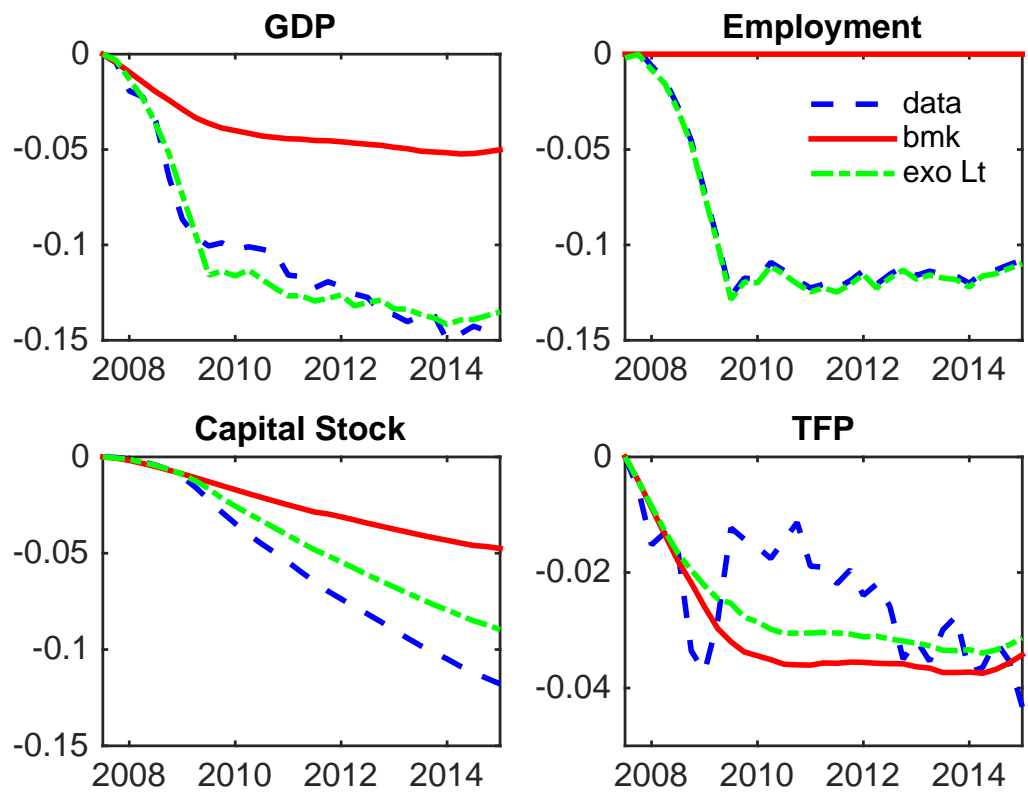

Figure 3: Great Recession in the benchmark model (solid line, bmk) and the model with exogenous hours (dash dotted line, exo Lt). The dashed line corresponds to the detrended data.

In Figure 3 we compare the detrended data for output, productivity, capital, and hours with the simulation of the model. The solid (red) line is the simulation of the model. The dashed (blue) line is the data. The two panels on the left show that the model captures the direction and persistence of the drops in capital and output - relative to trend - but misses the magnitudes: it explains only around one third of the drop in both output and capital. The lower right panel shows that the model does a decent job at tracking the behavior of productivity, missing the high frequency movements. It is important to highlight that no parameter has been chosen to fit this curve - or any of the other pictures in this figure! The lower left panel shows that the model, with constant labor, misses the behavior of hours. One could conjecture, therefore, that part of the reason why the model misses the magnitudes in explaining output and capital is related to the failure in explaining labor. One way to evaluate this conjecture, given that in the model labor supply is exogenous, is to simply impose

\footnotetext{
${ }^{33}$ As we show below, adding sticky wages à la Calvo cannot explain the persistent drop in labor either. The effects in the model last less than three years.
} 
in the simulation the behavior of hours that we saw in the data. The result is depicted in Figure 3 with the dashed-dotted (green) line. Once we feed the observed value for hours into the model, it decently passes an eyeball inspection of the figure.
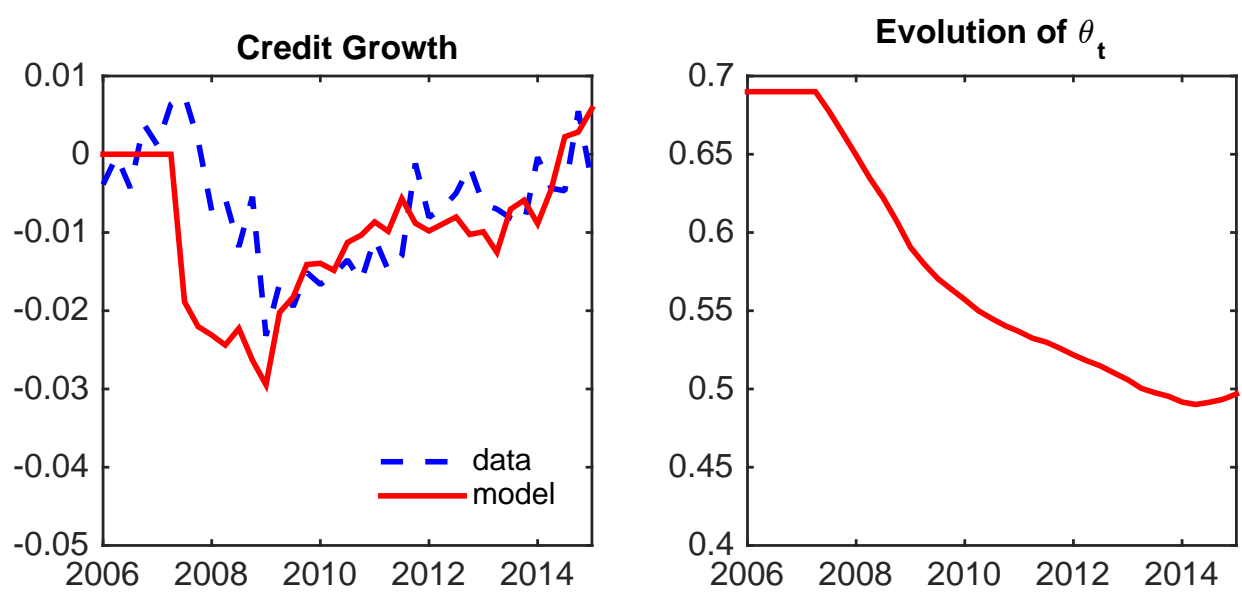

Figure 4: Credit growth and evolution of the (calibrated) collateral constraint $\theta$. The left panel compares credit growth in the benchmark model (solid line) and the data for the nonfinancial business sector (dashed line).

As an additional evaluation of the model, we compare the behavior of credit growth in the model - equal to the growth of the product of capital times the collateral constraint - with the recent evidence in the United States. The solid line in the left panel of Figure 4 shows the path for the growth rate of credit in the calibrated model. We also show the growth rate of credit to the nonfinancial business sector, normalized by the average growth in the 1997:Q2-2007:Q2 period (dashed line). While there is substantial correlation between the data and the model, the simulation overpredicts the speed with which credit drops in the data. The right panel shows the evolution of the collateral parameters $\theta_{t}$.

A natural caveat regarding the model is that debt contracts have one-period maturity, so the speed at which firms are forced to deleverage is very high. In the data, debt contracts last for many periods, and they take a few periods to get processed, approved, and executed. Thus, the comparison between the model that abstracts from all these lags and the data is trickier than what appears at first sight. ${ }^{34}$ All in all, it can be seen that, indeed, a big change occurs in 2007:Q3, the quarter that the real interest rate identifies as the beginning of the crisis.

\footnotetext{
${ }^{34}$ We would like to highlight, though, that the maturity structure should not matter for the steady state, so we feel comfortable with using the credit to non-financial assets ratio to calibrate $\theta$ in the steady state.
} 
Notice that the growth rate of credit almost fully recovers by the end of our sample. Would this indicate that the crisis may be reverting (in the model, credit to capital starts growing when the collateral parameter starts growing) and the main variables will now begin converging to its trend, putting an end to the "secular stagnation"? This model certainly implies so, with the exception of labor input, with its corresponding impact on output and capital.

Micro evidence that is consistent with a large contraction of credit affecting business firms during the Great Recession is presented by Chodorow-Reich (2014). Using a panel of banking relationships and employment for non financial firms, he shows that firms that had pre-crisis relationships with less healthy lenders had a lower likelihood of obtaining loans and reduced employment further following the Lehman bankruptcy. Consistent with our model, Kehrig (2015) presents evidence that the dispersion of productivity is countercyclical and that during the Great Recession the dispersion increase was the largest ever and pervasive across sectors.

Taken all together, these exercises provide evidence that the mechanism discussed in the model captures reasonably well many of the relevant features of the post-2007 events, with the big exception being the behavior of hours. ${ }^{35}$

The interpretation provided by the model, then, is that the credit crunch lasted at least eight years, with some weak indication that some reversal may be taking place: the real interest rate seems to be trending upward and credit growth, although very small, became positive at the end of 2014. The two facts are consistent with the gradual unwinding of the financial shock.

To summarize, in our view, the model decently passes an eyeball inspection of the recent events, once the current policy is taken into account. With this acceptable background, we now use the model to study the effect of policy.

\subsection{Alternative Policy Responses}

Was the policy response to the financial crisis, that is, the large increase in the supply of liquidity, instrumental in avoiding an even larger recession? What would have been the consequences of an even more aggressive response? To explore these questions we use our calibrated model to analyze alternative policy responses.

For all the experiments we consider, we proceed as before: we start the economy

\footnotetext{
${ }^{35}$ One could conjecture that modeling an elastic labor supply could improve the model's performance along this front. We show in the Online Appendix, Section E.2, that this is not the case.
} 
at the steady state and assume that in the first period, agents learn that there will be a deterministic credit crunch as calibrated in the previous section. All remaining parameters are also kept at the calibrated values. We then consider different scenarios for monetary and debt policy.

First, we illustrate the predicted evolution for the economy purely as a result of the credit crunch, in the absence of any policy response, so we maintain total liquidity at its initial value which is $62 \%$ of initial GDP. This case allows us to identify the pure effect of policy in the model. For this case, we also consider extensions with nominal debt and sticky wages. Second, we assume that monetary and fiscal policies are such that inflation is kept low and constant at alternative targeted values that are consistent with the typical mandates of central banks. To achieve the desired target, monetary and fiscal policy must be active, and the equilibrium outcome will depend on the accompanying debt, tax, and transfer policies. Thus, we consider alternative lump-sum tax and subsidy schemes.

\subsubsection{Nonresponsive Policy}

We now assume that the quantity of money and bonds remains fixed all the time and let lump-sum taxes be enough to cover interest payments, so $T_{t}^{e}=T_{t}^{w}=r_{t} B_{0}$ for all $t$.
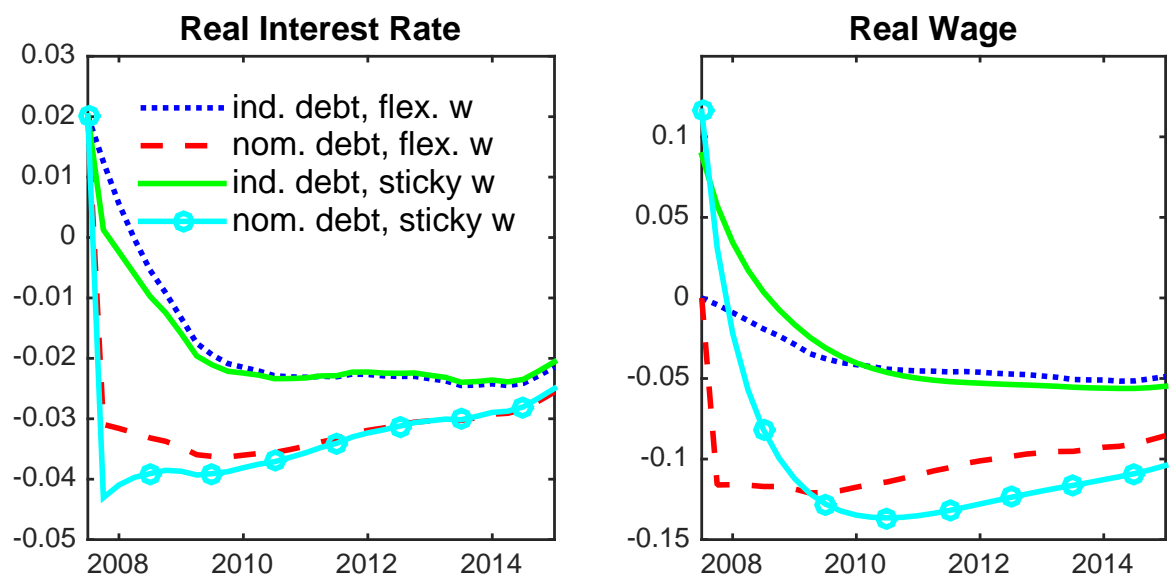

Figure 5: Factor prices with a nonresponsive policy, under alternative nominal frictions: (i) indexed debt and flexible wages (dotted line), (ii) nominal debt and flexible wages (dashed line), (iii) indexed debt and sticky wages (solid line), (iv) nominal debt and sticky wages (solid-circled line).

In Figures 5 and 6, we present results for the benchmark model as discussed so far, and for extensions that allow for both nominal debt, sticky wages and both. The 
results for the benchmark case with indexed debt and flexible wages (blue dotted line) are consistent with the theoretical results of the special case model discussed in Section 3.3. A credit crunch results in a large decline in the real interest rate, which bottoms out at minus 3\%(left panel of Figure 5), which is over 100 basis points larger than the drop in the benchmark model with the observed policy response, which bottoms out at minus 2\% (left panel of Figure 1).
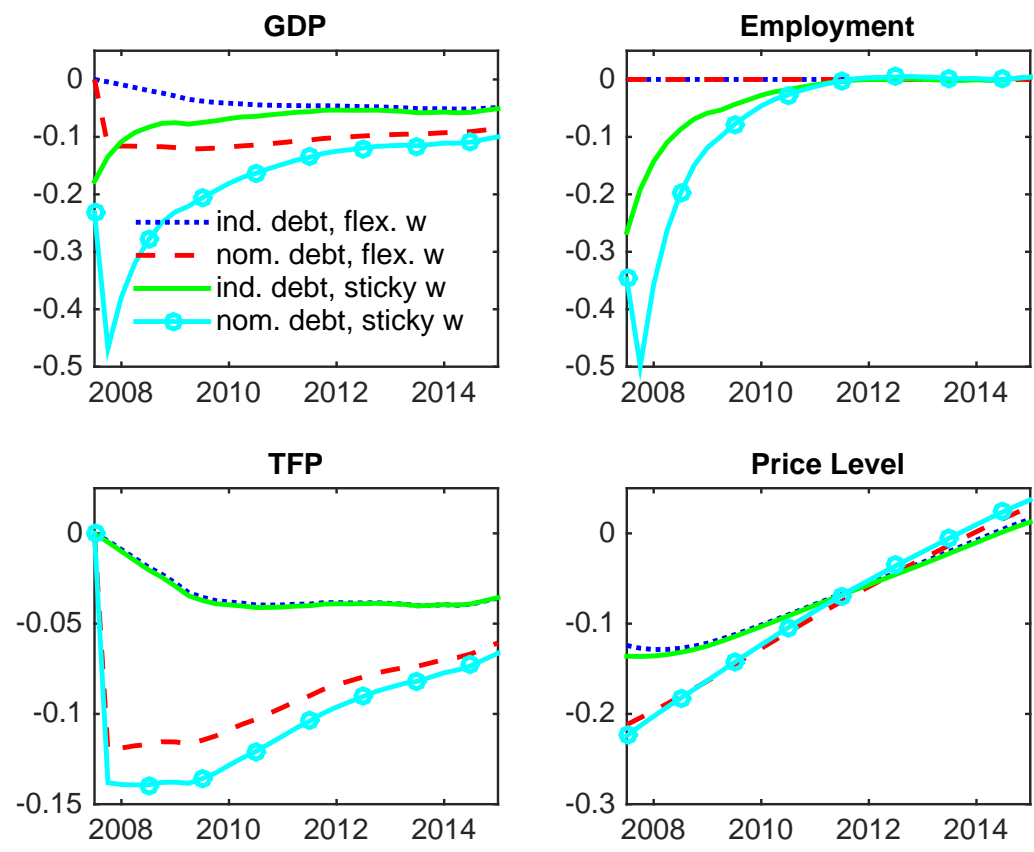

Figure 6: Macro aggregates with a nonresponsive policy, under alternative nominal frictions: (i) indexed debt and flexible wages (dotted line), (ii) nominal debt and flexible wages (dashed line), (iii) indexed debt and sticky wages (solid line), (iv) nominal debt and sticky wages (solid-circled line).

The lower right panel of Figure 6 reports the evolution of the price level where a deflation of around $15 \%$ occurs. ${ }^{36}$ In the context of the benchmark model, the deflation has little effect. But the results suggest that a potential problem may arise if debt instruments are nominal obligations or if there is downward wage rigidity, as the New Keynesian models assume. ${ }^{37}$ We now discuss these two extensions.

\footnotetext{
${ }^{36}$ In this perfect foresight equilibrium, the deflation occurs on impact. This feature would be different if, for instance, every period there is a constant probability of exiting the credit crunch.

${ }^{37}$ This "debt deflation" problem has been mentioned as one of the possible costs of deflations before, particularly in reference to the Great Depression (Fisher, 1933).
} 
Nominal Bonds We next consider the case in which entrepreneurs and the government issue nominal bonds only. As before, the real value of bond issuance is restricted by the collateral constraint. The results, which are substantially different, are given by the red dashed line in Figures 5 and 6 . The recession is deeper and more persistent, driven mainly by a sharper decline in TFP (lower left panel of Figure 6). The intuition for the large negative effect of the debt deflation is simple: the ability of productive entrepreneurs to invest is now hampered by both the tightening of collateral constraints and the decline in their net worth. As a consequence, a larger decline in the real interest rate must occur so that in equilibrium more capital is reallocated from productive to unproductive entrepreneurs (left panel of Figure 5), which results in a larger deflation and a nominal interest rate that remains at zero for a longer period of time (lower right panel of Figure 6).

This example shows that the initial deflation can be very costly in terms of output and could provide motivation for policy interventions to stabilize the price level and output. An alternative motivation is given by the existence of nominal rigidities.

Sticky Wages We now consider the model with restrictions in the setting of nominal wage rigidities, following the New Keynesian tradition. In particular, we consider workers that are grouped into households, with a continuum of members supplying differentiated labor inputs. Each member of the household is monopolistically competitive and gets to revise the wage in any given period with a constant probability, as in Calvo (1983). A detailed description of this extension and the calibration, which are totally standard in the literature, is provided in the Online Appendix, Section D.

The solid green line in Figures 5 and 6 shows the evolution of the economy for the case with rigid wages. As in the first example, we assume that private bonds are indexed to the price level and the supply of money and bonds remains constant. With rigid wages, the initial deflation causes an increase in the real wage (right panel of Figure 5) and a sharp decline in labor input (top right panel of Figure 6). This results in a substantially more severe recession. As in the previous examples in this figure, the real interest rate becomes negative and the nominal interest rate is at the zero lower bound for various periods. Unlike the case with nominal debt contracts, the presence of frictions in the setting of wages does not result in important effects on TFP. ${ }^{38}$

\footnotetext{
${ }^{38}$ Note that for this parameterization, which follows the literature, the effect of sticky wages on the evolution of total hours lasts about two and a half years. Thus, while the size of the drop in labor is almost the same as in the data, it reverts nuch too fast in the model.
} 
Interactions of Nominal Frictions Is there an interesting interaction between these two nominal frictions, nominal debt contracts and sticky nominal wages? The dramatic dynamics illustrated by the solid lines with circle markers in Figures 5 and 6 , which corresponds to that of an economy with nominal debt contracts and sticky wages, provides a loud answer to this question. As discussed, with nominal debt contracts, the credit crunch results in a large redistribution of wealth from debtors (productive entrepreneurs) toward creditors (unproductive entrepreneurs). This implies a lower real interest rate and a larger initial deflation. With sticky wages, initially the real wage is larger, and therefore, there is a substantially larger drop in employment. This feeds back into a lower profitability of productive entrepreneurs and lower TFP.

The previous discussion suggests that the initial deflation can be very costly in terms of output. An obvious question, then, is what can monetary and fiscal policy do, if anything, to stabilize the price level and output? We analyze these questions next.

\subsubsection{Inflation Targeting}

We now consider the cases in which the government implements alternative inflation targets, which for simplicity we assume constant, $\pi$. We compare these cases with the benchmark economy, which we calibrate to the US experience during the financial crisis. This is a particular example of the policies described in this section, where the inflation target is the path of inflation in the data.

As long as the zero bound does not bind, so $r_{t}>-\frac{\pi}{1+\pi}$, inflation is determined by standard monetary policy. However, if given the target, the natural interest rate is inconsistent with the zero bound, the government needs to increase real money balances $M_{t+1} / p_{t}$, government bonds $B_{t+1}$, or both, in order to satisfy the excess demand for real assets. In order to do so, it will also need to implement a particular scheme of taxes and transfers, and the way in which this scheme is implemented is quantitatively critical in this non-Ricardian economy. Indeed, equation (15) makes clear that the ones that matter are the transfers (or taxes) to the entrepreneurs that discount the future at rates that are different from the equilibrium interest rate. These are the active entrepreneurs.

We consider two simple cases. First, as in the benchmark calibration, we consider the case in which taxes are purely lump-sum for all periods. But in periods when the government increases the supply of bonds, we assume that the proceeds from the sale of bonds, net of interest payments and the adjustment of the supply of real balances, 
are transferred only to the entrepreneurs, so $T_{t}^{W}=0$ whenever $T_{t}^{e}<0$. This case captures a scenario in which the government responds to a credit crunch by bailing out productive entrepreneurs and bondholders. We refer to this as the "bailout" case. ${ }^{39}$

The second case that we consider is one in which taxes (transfers) are purely lumpsum, that is, $T_{t}^{W}=T_{t}^{e}$ for all $t, z$. We refer to this as the "lump-sum" case. As we will show, this case exhibits an even larger departure from Ricardian equivalence, since workers eventually hit their no borrowing limit in finite time, so Ricardian equivalence also fails for them. ${ }^{40}$
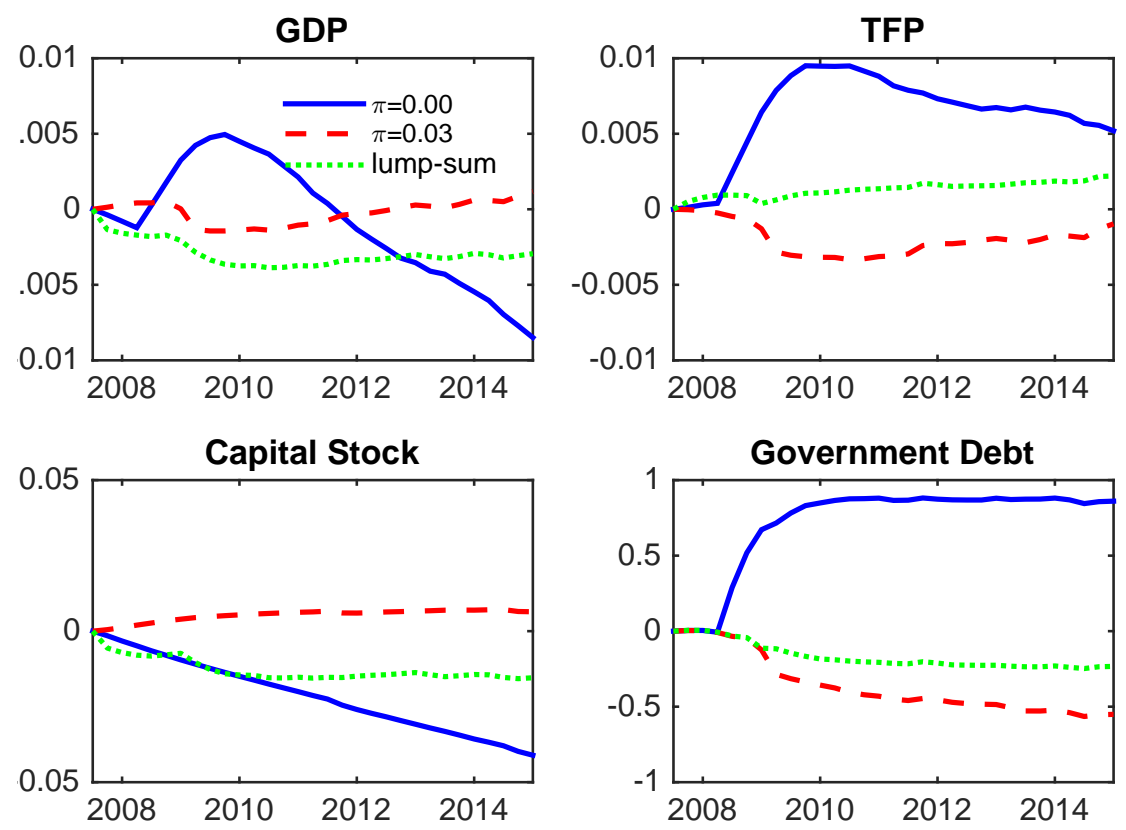

Figure 7: Macro aggregates with alternative inflation targets and transfer scheme. The solid and dashed lines report the cases with an inflation target of $0(\pi=0.00)$ and $2 \%(\pi=0.02)$, respectively. The dotted line corresponds to the case in which transfers are lump-sum, but inflation is as in the benchmark case. We report log deviations from the benchmark case shown in Figure 3.

We now address the question, can the government mitigate the consequences of the credit crunch by choosing alternative inflation targets? In particular, is it desirable for the government to choose a sufficiently high inflation target in order to avoid the zero lower bound? We explore these questions in Figure 7. There we present the evolution

\footnotetext{
${ }^{39}$ The transfer to bondholders is consistent with the evidence presented by Veronesi and Zingales (2010) for the bailout of the financial sector in 2008.

${ }^{40}$ In the derivation of equation (15), we assumed that workers were hand to mouth, but this is not the case in the simulations we present in this section. The only agents for which Ricardian equivalence holds are inactive entrepreneurs.
} 
of two economies differing in the level of the inflation target, $\pi=0$ (solid line) and $\pi=0.03$ (dashed line). In these two cases, we assume that the government rebates the proceeds from the increase in the debt solely to entrepreneurs (bailout case). The variables are presented as log deviations from the benchmark economy, where policy implements the observed path of inflation, close to $2 \%$ per year.

To avoid the deflation induced by the excess demand of mediums to serve as a "store of value," the government must increase the supply of government bonds plus money. The required increase in the supply of liquidity is a decreasing function of the desired inflation target (Figure 7, lower right panel). For instance, to implement the case with zero inflation, the government needs to engineer a path with zero real interest rates during the credit crunch. This requires an increase in the supply of liquidity that is over $50 \%$ larger than in the benchmark case. On the contrary, a path with sufficiently high inflation, for example, $\pi=0.03$ in our calibration, can be implemented with an arbitrarily small increase in the supply of liquidity. The key difference is that when the inflation target is large enough, the economy does not enter a liquidity trap, and therefore inflation is determined by standard monetary policy and not by the behavior of the real interest rate.

As the top left panel of Figure 7 shows, with a lower inflation target, the government accomplishes a slightly less pronounced recession at the cost of a significantly more protracted recovery. The milder recession is explained by the smaller drop in TFP (top right panel). To attain low inflation, the real interest rate needs to be higher (less negative), and therefore there is less reallocation of capital toward less productive, and previously inactive, entrepreneurs. The counterpart of the milder drop in TFP is a collapse in investment, leading to a substantial and persistently larger decline in the stock of capital (bottom left panel).

In our framework, and as explained above, increases in government debt crowd out private investment, since constrained entrepreneurs discount future taxes using the return to their project, which is higher than the interest rate. In addition, even inactive entrepreneurs increase their consumption because the transfers they receive outweigh the present value of taxes, since workers are also taxed and not subsidized. The consumption of workers does not respond to future taxes because they are liquidity constrained after the first two periods.

The crowding out of private investment is true for both ways of designing the tax and transfer scheme, as illustrated by the dotted line in Figure 7. The dotted line 
shows the evolution of a counterfactual economy in which the government implements the same inflation target as in the benchmark case, using purely lump-sum taxes and subsidies. Note, however, that the magnitude of the crowding out is much higher when the government uses pure lump-sum taxes. In this case, part of the transfers go to workers, who in equilibrium have a large marginal propensity to consume, since they will be up against their borrowing constraint in finite time. ${ }^{41}$ In comparison to the lump-sum case, the recovery is faster when the government rebates the proceeds from the increase in the debt solely to entrepreneurs. ${ }^{42}$

The case of a government implementing a low inflation rate seems to be an attractive approach to interpreting the Great Recession in the United States. Following the 2008 crisis, the economy has been at the zero bound for several quarters, while the Fed has substantially increased its balance sheet. The Fed policy has been directed explicitly to provide the US economy with safe zero nominal interest rate money-like assets, while inflation has been under total control. In the same direction, the federal government has substantially increased its indebtedness (supply of real assets). All of these features are reproduced by this example. Moreover, the presumption is that these policies avoided a more severe recession, although the recovery is seen as unusually slow - again, a feature of the aggregate economy in our benchmark example. ${ }^{43}$

While the figures in this section suggest a relatively simple trade-off at the aggregate level, these dynamics hide very disparate effects of a credit crunch and alternative policies among different agents. Although workers are hurt by the drop in wages, the profitability of active entrepreneurs and their welfare can increase as a result of lower factor prices. Similarly, unproductive entrepreneurs are bondholders in equilibrium, and therefore their welfare depends on the behavior of the real interest rate. A full analysis of the distribution of welfare impacts is presented in the Online Appendix, Section C.

\footnotetext{
${ }^{41}$ In a steady state, the interest rate is strictly lower than the rate of time preferences, $\left(1+r_{\infty}\right) \beta<1$. Therefore, workers, who earn a flow of labor income each period, will choose to be up against their borrowing constraint in finite time.

${ }^{42}$ See the Online Appendix, Section B, for analytical comparative static results of the effect of changes in government debt in the neighborhood of $B_{1}=0$ for the simple example introduced in Section 3.3. There we consider the case in which all taxes and transfers are made to entrepreneurs, and the polar case in which workers are the only agents that are taxed and receive transfers.

${ }^{43}$ As a referee pointed out, the model can be used to compute transitions back to the steady state if the collateral constraint goes back to levels that were prevalent before the crisis and credit growth recovers, as well as alternative cases. We provide such exercises in the Online Appendix, Section E.3.
} 


\section{Conclusions}

A contraction in credit due to a tightening of collateral constraints leads to a recession and a drop in the return of safe assets. In a monetary economy, the nominal return on safe assets cannot be negative, so the negative of the rate of inflation is a lower bound on its real return. We showed that if the contraction in credit is large enough, then this constraint becomes binding and the economy enters a liquidity trap. In this case, a deflation occurs if policy is passive. This deflation may interact with collateral constraints, creating debt deflation and worsening the recession if debt obligations are in nominal terms. In addition, it creates a large drop in employment if wages are sticky.

We characterize a policy that avoids that costly deflation. That policy resembles the one followed by the Federal Reserve as a reaction to the 2008 crisis and is in line with Friedman and Schwartz's (1963) explanation of the severity of the Great Depression.

The policies that avoid the deflation involve a large increase in money or bonds, which are perfect substitutes at the zero bound. These policies do stabilize prices and output, but they have a side effect: they generate a slow recovery. We argue that many of the features of the model capture the characteristics of the last financial crisis that hit the United States starting in 2008. It also sheds new light on the events that unraveled in Japan in the early 1990s and continue until today.

The interpretation of the crisis provided by the model in this paper is in contrast to the dominant view in most central banks and is supported by a literature that emphasizes price frictions. According to that literature, it is unambiguously optimal to maintain the economy at the zero bound even after the reversion of the shock that drove real interest rates to negative values. The model of this paper implies that avoiding the zero bound or not involves nontrivial trade-offs: ameliorating the drop in output at the cost of a slower recovery. The policy trade-offs are even more subtle when the heterogeneous effects across agents are taken into account.

Our model rationalizes the notion that the inflation determination mechanisms differ substantially when the policy authority decides to be at the zero bound. Away from the zero bound, it depends on standard monetary mechanisms. But at the zero bound, it is total outside liabilities that matter: inflation can be controlled only by managing the real interest rate so that it does not become too negative. 


\section{References}

Andrea, , L. Benzoni, And O. Chyruk (2012): "Core and 'Crust': Consumer Prices and the Term Structure of Interest Rates," Manuscript, Research Department, Federal Reserve Bank of Chicago.

Bagnall, J., D. Bounie, K. P. Huynh, A. Kosse, T. Schmidt, S. Schuh, And H. Stix (2014): "Consumer Cash Usage: A Cross-Country Comparison with Payment Diary Survey Data," Working Papers 192, Oesterreichische Nationalbank (Austrian Central Bank).

Bernanke, B. And M. Gertler (1989): "Agency Costs, Net Worth, and Business Fluctuations," American Economic Review, 79, 14-31.

Bernanke, B. S., M. Gertler, and S. Gilchrist (1999): "The Financial Accelerator in a Quantitative Business Cycle Framework," in Handbook of Macroeconomics, ed. by J. B. Taylor and M. Woodford, Elsevier, vol. 1 of Handbook of Macroeconomics, chap. 21, 1341-1393.

Brunnermeier, M. K. And Y. Sannikov (2013): "The I Theory of Money," Manuscript, Princeton University.

Buera, F. J. AND B. Moll (2015): "Aggregate Implications of a Credit Crunch: The Importance of Heterogeneity," American Economic Journal: Macroeconomics, $7,1-42$.

Calvo, G. A. (1983): "Staggered Prices in a Utility-Maximizing Framework," Journal of Monetary Economics, 12, 383-398.

Chodorow-Reich, G. (2014): "The Employment Effects of Credit Market Disruptions: Firm-level Evidence from the 2008-9 Financial Crisis," Quarterly Journal of Economics, 129, 1-59.

Christiano, L., M. Eichenbaum, And S. Rebelo (2011): "When Is the Government Spending Multiplier Large?" Journal of Political Economy, 119, 78-121.

Cooley, T., R. Marimon, And V. Quadrini (2004): “Aggregate Consequences of Limited Contract Enforceability," Journal of Political Economy, 112, 817-847.

Correia, I., E. Farhi, J. P. Nicolini, And P. Teles (2013): "Unconventional Fiscal Policy at the Zero Bound," American Economic Review, 103, 1172-1211. 
Curdia, V. And G. Eggertsson (2009): "What Caused the Great Depression?" Manuscript, Federal Reserve Bank of New York.

Eggertsson, G. B. And M. Woodford (2003): "The Zero Bound on Interest Rates and Optimal Monetary Policy," Brookings Papers on Economic Activity, 34, 139-235.

Fisher, I. (1933): "The Debt-Deflation Theory of Great Depressions," Econometrica, $1,337-357$.

Friedman, M. And A. Schwartz (1963): A Monetary History of the United States, 1867-1960, Princeton, NJ: Princeton University Press.

Guerrieri, V. And G. Lorenzoni (2011): "Credit Crises, Precautionary Savings, and the Liquidity Trap," Working Paper 17583, National Bureau of Economic Research.

Hsieh, C.-T. And P. J. Klenow (2009): "Misallocation and Manufacturing TFP in China and India," The Quarterly Journal of Economics, 124, 1403-1448.

JERMANN, U. AND V. QUADRINI (2012): "Macroeconomic Effects of Financial Shocks," American Economic Review, 102, 238-271.

Kaplan, G. and G. L. Violante (2014): "A Model of the Consumption Response to Fiscal Stimulus Payments," Econometrica, 82, 1199-1239.

Kenrig, M. (2015): "The Cyclical Nature of the Productivity Distribution," Manuscript, University of Texas at Austin.

Kiyotaki, N. (1998): "Credit and Business Cycles," Japanese Economic Review, 49, $18-35$.

Kiyotaki, N. And J. Moore (1997): "Credit Cycles," Journal of Political Economy, $105,211-48$.

(2012): "Liquidity, Business Cycles, and Monetary Policy," Working Paper 17934, National Bureau of Economic Research.

LucAs, R. E. J. (1982): "Interest Rates and Currency Prices in a Two-Country World," Journal of Monetary Economics, 10, 335-359.

Moll, B. (2014): "Productivity Losses from Financial Frictions: Can Self-Financing Undo Capital Misallocation?" American Economic Review, 104, 3186-3221. 
Svensson, L. (1985): "Money and Asset Prices in a Cash-in-Advance Economy," Journal of Political Economy, 93, 919-944.

Veronesi, P. And L. Zingales (2010): "Paulson's Gift," Journal of Financial Economics, 97, 339-368.

Werning, I. (2011): "Managing a Liquidity Trap: Monetary and Fiscal Policy," Working Paper 17344, National Bureau of Economic Research. 